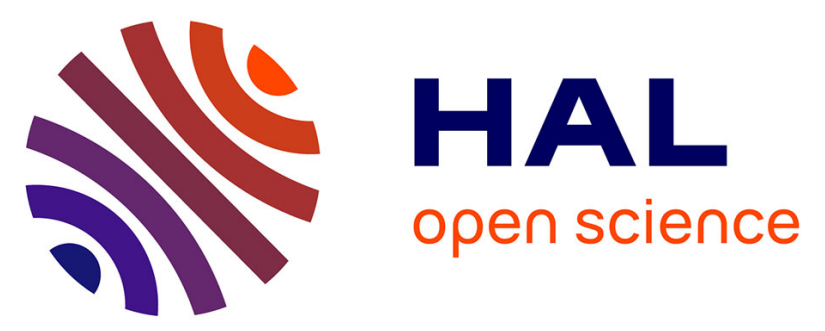

\title{
Emphasis on the Properties of Metal-Containing Zeolites Operating Outside the Comfort Zone of Current Heterogeneous Catalytic Reactions
}

Edwin Clatworthy, Stanislav Konnov, Florent Dubray, Nikolai Nesterenko, Jean-pierre Gilson, Svetlana Mintova

\section{To cite this version:}

Edwin Clatworthy, Stanislav Konnov, Florent Dubray, Nikolai Nesterenko, Jean-pierre Gilson, et al.. Emphasis on the Properties of Metal-Containing Zeolites Operating Outside the Comfort Zone of Current Heterogeneous Catalytic Reactions. Angewandte Chemie, 2020, Chemie poröser funktioneller Materialien, 132 (44), pp.19582-19600. 10.1002/ange.202005498 . hal-02968398

\section{HAL Id: hal-02968398 \\ https://hal.science/hal-02968398}

Submitted on 26 Nov 2020

HAL is a multi-disciplinary open access archive for the deposit and dissemination of scientific research documents, whether they are published or not. The documents may come from teaching and research institutions in France or abroad, or from public or private research centers.
L'archive ouverte pluridisciplinaire HAL, est destinée au dépôt et à la diffusion de documents scientifiques de niveau recherche, publiés ou non, émanant des établissements d'enseignement et de recherche français ou étrangers, des laboratoires publics ou privés. 


\section{Emphasis on the properties of metal-containing zeolites operating outside the comfort zone of current heterogeneous catalytic reactions}

Edwin B. Clatworthy, ${ }^{[a]}$ Stanislav V. Konnov ${ }^{[a]}$ Florent Dubray, ${ }^{[a]}$ Nikolai Nesterenko, ${ }^{[b]}$ Jean-Pierre Gilson, ${ }^{[a]}$ Svetlana Mintova*[a]

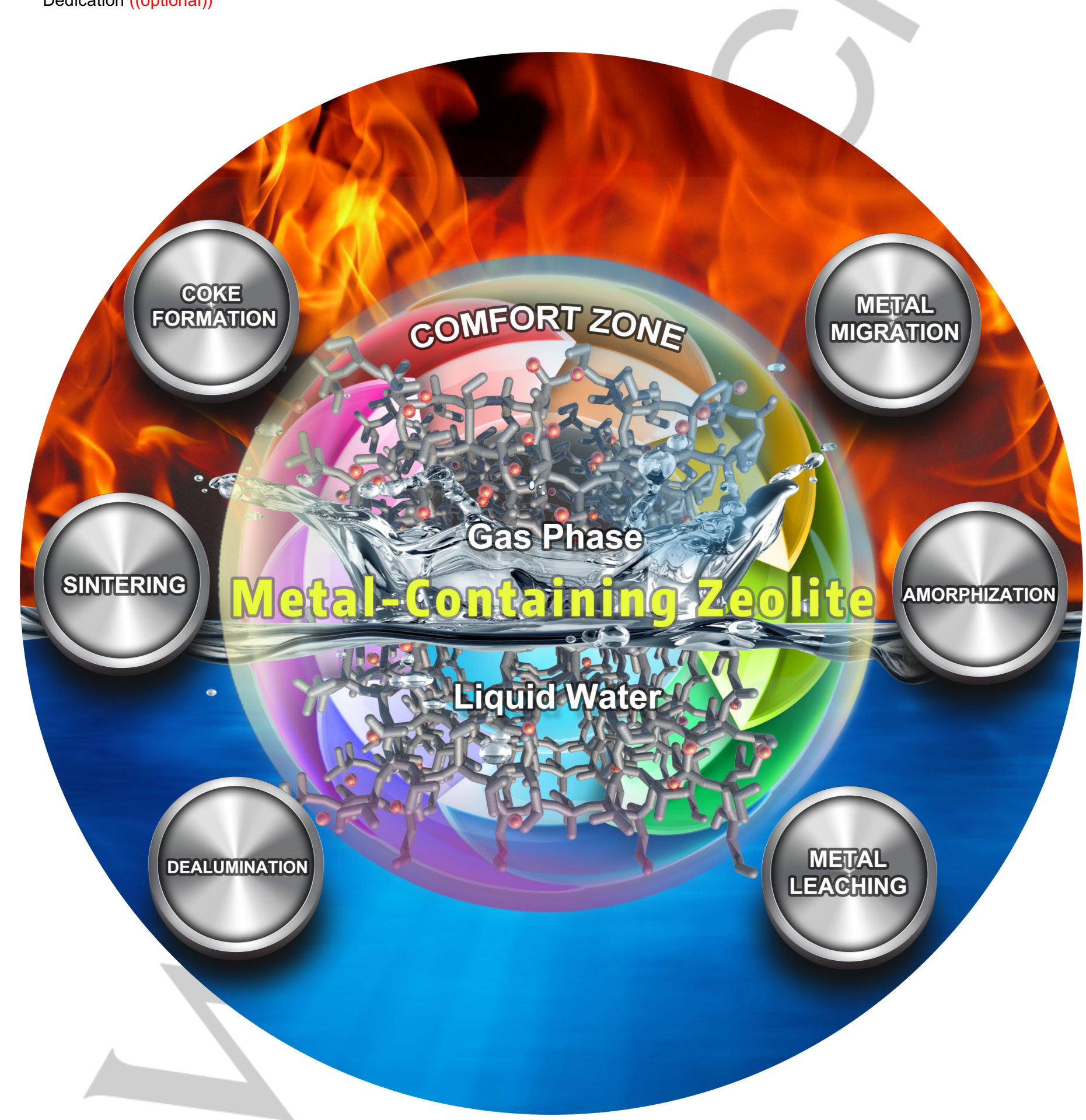


WILEY-VCH

[a] Dr. E.B. Clatworthy, Dr. S.V. Konnov, Mr. F. Dubray, Prof. J.-P. Gilson, Dr. S. Mintova Laboratoire Catalyse et Spectrochimie (LCS)

Normandie Université, ENSICAEN, UNICAEN, CNRS

6 Boulevard du Maréchal Juin, 14050, Caen, France

E-mail: svetlana.mintova@ensicaen.fr

[b] Dr. Nikolai Nesterenko

Total Research and Technology

Feluy, B-7181 Seneffe, Belgium

\begin{abstract}
The development of catalysts that can operate under exceptionally harsh and unconventional conditions is of critical importance for the transition of the energy and chemicals industries to low-emission and renewable chemical feedstocks. In this review we will highlight materials and more specifically metal-containing zeolite catalysts that have been tested under harsh reaction conditions such as high temperature light alkane conversion and biomass valorization. Particular attention will be given to studies that explore the stability and recyclability of metal-containing zeolite catalysts operating in continuous modes. Metal-containing zeolites are considered as an important class of catalysts operating outside the comfort zone of current heterogeneous catalytic reactions in both gas and liquid phase reactions. The relationship between the properties of the metalcontaining zeolite and catalytic performance will be explored.
\end{abstract}

\section{Introduction}

The global energy system is undergoing a significant transition in response to a number of major challenges including the reduction of greenhouse gas emissions. ${ }^{[1]}$ Projections of the demand for liquids (transportation fuels and naphtha) over the next halfcentury predict an increase in the ratio of petrochemicals to fuels as the global population and living standards continue to rise. ${ }^{[2]}$ To satisfy both an increase in petrochemical production and a decrease in global emissions, alternative energy sources and processes will need to be established which will require the development of new catalysts possessing unique and exceptional properties.

Zeolites have proven to be game-changing materials in the petrochemical industry over the last 50 years, and due to their established position have the potential to readily facilitate the development of new and emerging petrochemical processes. ${ }^{[3]}$ Two examples include (1) the non-oxidative conversion of $\mathrm{CH}_{4}$ and (2) the valorization of biomass. Both present attractive options for the production of $\mathrm{H}_{2}$ and chemicals, however, they typically occur outside the comfort zone of conventional heterogeneous catalytic reactions. The conditions required for such reactions involve either high temperatures $\left(>550^{\circ} \mathrm{C}\right)$ or hot aqueous solvents, making the control of the catalyst performance (activity, selectivity, and stability) exceptionally challenging.

It is well-known that metal-containing zeolites which operate at high temperature, in the presence of steam, or in hot aqueous solvents suffer from several types of irreversible damage including: (i) loss of dispersion of the metal phase, ${ }^{[4]}$ (ii) leaching of the metal phase, ${ }^{[5]}$ (iii) severe dealumination due to the reaction between volatile metals and framework $\mathrm{Al}{ }^{[6]}$ and (iv) acid/base catalyzed hydrolysis of $\mathrm{Si}-\mathrm{O}-\mathrm{Al} / \mathrm{Si}-\mathrm{O}-\mathrm{Si}$ bonds. ${ }^{[7]}$ In addition, the formation of coke from $\mathrm{CH}_{4}$ and biomass-derived substrates can result in the poisoning of acid sites and the blocking of pores. ${ }^{[8]}$ Regeneration of the catalyst by calcination can remove coke deposits but often results in the sintering of the metal phase by Ostwald ripening and particle migration. ${ }^{[9]}$ The dispersion of the metal phase can be restored in some cases via a combination of reductive/oxidative treatments but it brings significant costs and reduces efficiency. Despite the general acceptance of these problems by both the industrial and academic communities, and the significance of these issues for industrial processes, they are seldom addressed in the open literature.

Significant progress has been made in the preparation of new zeolite structures and morphologies, such as nanozeolites and hierarchical zeolites, yet their stability and regeneration require further investigation and improvement. Several strategies to address the hydrothermal stability of zeolites have been developed: ${ }^{[10]}$ synthesis in fluoride media affording hydrophobic zeolites with a low number of defects, ${ }^{[11]}$ post-synthetic silane treatment to protect the zeolite surface from attack by condensed water, ${ }^{[12]}$ post-synthetic modification with phosphorous, ${ }^{[13]}$ or ionexchange with rare-earth metals, ${ }^{[14]}$ resulting in reduced dealumination. However, some of these methods require the use of extremely hazardous reagents, such as HF, and can result in changes to the concentration, strength and access to acid sites. ${ }^{[15]}$ In addition, the relatively small number of comprehensive studies concerning the stability and recyclability of metal-containing zeolite catalysts operating in continuous modes presents as a significant obstacle to the identification and development of practical solutions to zeolite deactivation. Valuable lessons could be learned from FCC, MTO and other mature technologies (all requiring catalyst stability in harsh environments, such as high temperature in the presence of steam), but in these cases the catalytically active phases are monofunctional, i.e. contain Brønsted acid sites only. ${ }^{[16]}$ In comparison to conventional substrates derived from crude oil, crude biomass and biomassderived molecules are usually processed in liquid (aqueous) phase and are typically of higher molecular weight and polarity, requiring the use of bifunctional catalysts. ${ }^{[17]}$ Solving the stability issues of metal-containing zeolites would significantly accelerate the development of advanced catalysts for processing natural gas and biomass feedstocks.

Zeolites (and zeotypes) that possess metals incorporated at the T-atom positions (tetrahedral $\mathrm{Si}$ or $\mathrm{Al}$ ) of the framework are a promising class of materials for operating under harsh and unconventional reaction conditions. The substitution of T-atoms for metals such as $\mathrm{Ti}, \mathrm{V}, \mathrm{Ga}, \mathrm{Mo}, \mathrm{Sn}$ or $\mathrm{W}^{\left[{ }^{18]}\right.}$ can result in beneficial changes to the catalyst such as: (1) tailored selectivity 
Edwin B. Clatworthy received his $\mathrm{PhD}$ (2019) from The University of Sydney, supervised by Assoc. Prof. Anthony F. Masters and Prof. Thomas Maschmeyer, on a combined investigation of homogeneous cobalt catalysts for water and biomass oxidation, and metal nitrides for photocatalytic hydrogen evolution. Currently, he is a postdoctoral researcher in the Laboratory of Catalysis and Spectrochemistry, Normandy University, CNRS, France. His current research interests focus on the synthesis of nanosized zeolites for applications in gas separation.

Stanislav V. Konnov received his PhD from Lomonosov Moscow State University, Laboratory of Kinetics and Catalysis, Russia in 2010, after which he joined A.V. Topchiev Institute of Petrochemical Synthesis (20102018). Currently, he is a postdoctoral researcher in the Laboratory of Catalysis and Spectrochemistry, Normandy University, CNRS, France. His research interests include synthesis and applications of porous solid materials, nanomaterials for energy and environmental catalysis.

Florent Dubray holds both an engineering title and a master degree in chemistry and material science from the University of Caen Normandy/ENSICAEN (2017), specializing in catalyst design and characterization. Currently, he is a $\mathrm{PhD}$ student in the Laboratory of Catalysis and Spectrochemistry, Normandy University, CNRS, supported by TOTAL, Research and Technology. His research interests focus on zeolite synthesis, specifically on the
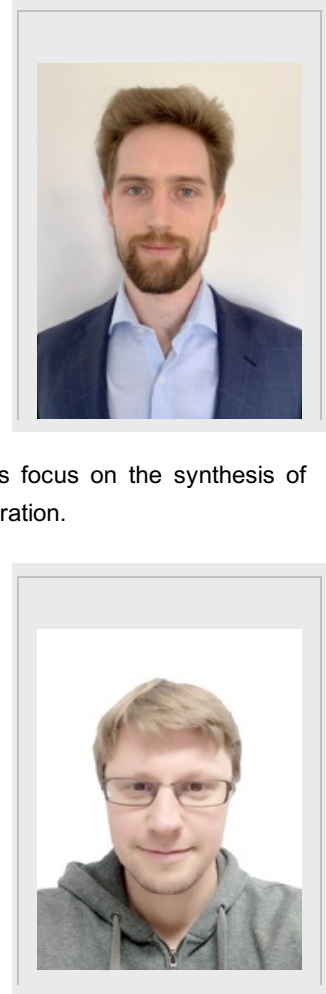

incorporation of transition metals in zeolites for catalytic applications. He is interested in the development of new methodology based on NMR and IR spectroscopy for characterization of zeolites and related porous materials.

Nikolai Nesterenko graduated cum-laude from Lomonosov Moscow State University (MSU), obtained $\mathrm{PhD}$ (Heterogeneous catalysis) in 2004 from University of Montpellier \& MSU. He joined the R\&D division of Total in 2005 in Belgium. Then, he completed EMBA (2014) at HULT International Business School in London (UK) and was appointed as the coordinator of R\&D program on conversion of natural gas and the head of the Industrial Chair Laboratory between Total and ENSICAEN (France) Dr. Nesterenko has proven experience within refining and chemicals, biomass \& natural gas upgrading, (co-) inventor of more than 100 patents; one of the key contributors in four industrializations of new technologies performed by Total.
Jean-Pierre Gilson is a Distinguished Professor at ENSICAEN, a University level French engineering school in Caen (France) where he also performs its research activities in the LCS (Laboratory of Catalysis and Spectrochemistry), a laboratory he directed for 3 terms of 4 years each. He is also an invited professor at the Dalian Institute of Chemical Physics and a foreign expert at Jilin University. Jean-Pierre had a dual industrial (UOP, Grace, Shell) and academic career

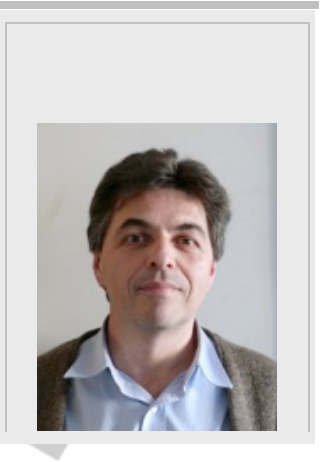
and managed during a 4-year attachment the extra-mural research of the downstream activities of Total. $\mathrm{He}$ is the co-recipient of the Industrial Chair NanoCleanEnergy funded by ANR (the French National Research Agency) and Total. He was in charge of the discovery and commercial deployment of 3 catalysts while in industry. His scientific interests include the preparation and shaping of catalysts, in particularly zeolite-based ones, their characterization by advanced techniques, evaluation in model reactions. He is very active in promoting academic-industrial cooperation in the fundamental aspects of catalysis.

Svetlana Mintova is Director of Research, 1st class in CNRS, Laboratory of Catalysis and Spectrochemistry, Normandy University, CNRS, France and Invited Professor in China University of Petroleum (UPC), Qingdao, China. Mintova is the receiver of the Baron Axel Cronstedt award from FEZA 2014, the Donald Breck award from the IZA 2016, the "Le Prix La Recherche Chimie" 2016, and Shandong International Science and Technology Cooperation award 2019.

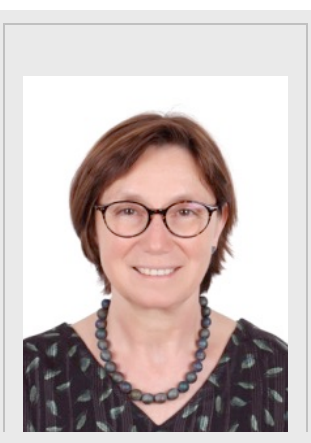

Mintova is the Council member of the IZA, FEZA and GFZ, and the Chair of the "Synthesis Commission" of the IZA. Her scientific interests include preparation of porous materials, nanosized zeolites, films, coatings, composites and related applications.

due to uniformly dispersed metal atoms that can form either closed (non-hydrolyzed) or open (hydrolyzed) Lewis-acidic framework-metal sites; ${ }^{[19]}$ (2) high hydrophobicity due to the reduction in the number of silanol defect sites; ${ }^{[20]}$ (3) improved mass transfer (in comparison with their impregnated or ionexchanged counterparts) due to the absence of metal particles that are formed within the micropores during post treatment procedures; ${ }^{[21]}(4)$ improved stability of the metal phase due to its high dispersion at low loading in the zeolite framework (reduced Ostwald ripening and metal mobility); and (5) reduced coking rate due to the high distance between/low density of active sites. However, the stability of the metal phase will depend significantly on the preferred coordination environment of the metal as a consequence of its electronic properties and ionic radius, as well as the nature of the site occupied by the metal for any given type of framework. In this review we highlight metal containing zeolites operating outside the "comfort zone" of current heterogeneous catalytic reactions. To that end we focus on research efforts over the last decade to develop materials that demonstrate stability under (i) high temperature $\left(\geq 550^{\circ} \mathrm{C}\right)$ conditions for gas phase hydrocarbon reactions, such as propane dehydrogenation and non-oxidative conversion of $\mathrm{CH}_{4}$, and (ii) aggressive liquid phase conditions such as hot $\left(\geq 100^{\circ} \mathrm{C}\right)$ aqueous solvents used for 


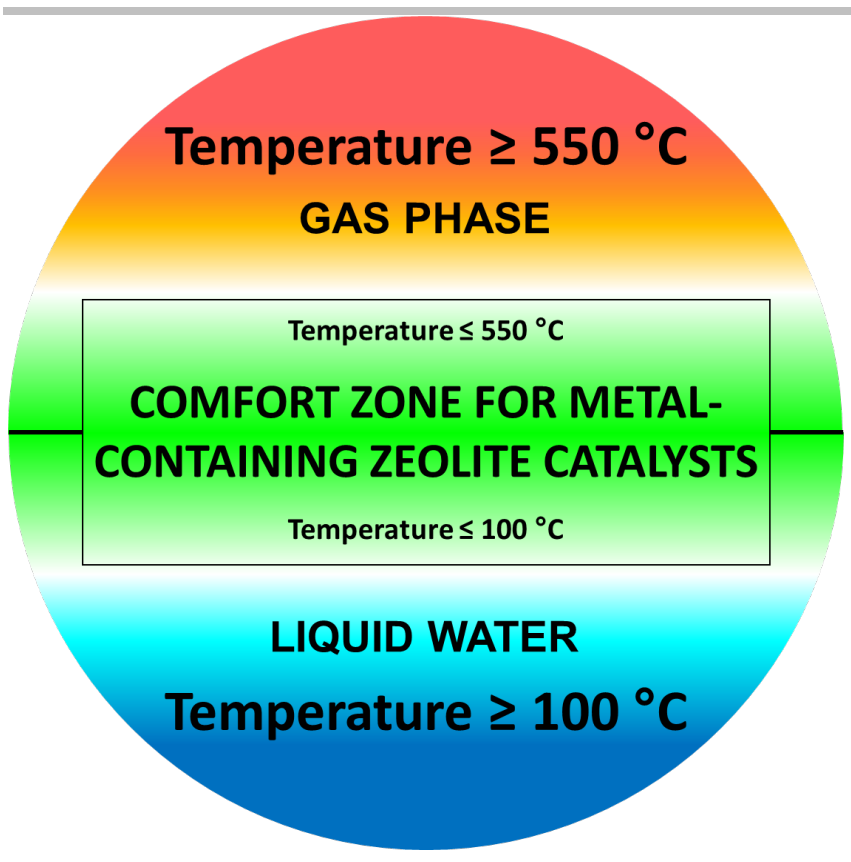

Figure 1. Conditions for metal-containing zeolite catalysts working inside and outside of the "comfort zone" defined here as, $\geq 550{ }^{\circ} \mathrm{C}$ for gas phase alkane conversion, and $\geq 100^{\circ} \mathrm{C}$ for liquid water phase biomass valorization.

biomass valorization reactions (Figure 1). Zeolite catalysts used in industrial and emerging processes at temperatures above 500 $550{ }^{\circ} \mathrm{C}$, particularly in the presence of steam, begin to significantly suffer from dealumination, metal migration, and in the case of $\mathrm{CH}_{4}$ conversion with Mo-ZSM-5, reaction of framework Al. ${ }^{[6,}{ }^{22]}$ In addition, much attention has been directed towards the behaviour of zeolites in water at temperatures around $100^{\circ} \mathrm{C}$, driven by the increasing interest in utilizing biomass feedstocks. ${ }^{[23]}$ For greater detail concerning topics touched upon in this review such as Lewis acid and Sn-containing zeolites, ${ }^{[19,24]}$ metals in zeolites, ${ }^{[18,}$ ${ }^{25]}$ and catalytic applications of zeolites for emerging methane and biomass valorization processes, ${ }^{[7 a, 26]}$ the reader is directed to these comprehensive sources. In this work, for each example we will seek to explore the relationship between the properties conferred by the introduction of the metal species into the zeolites and the catalytic behavior of the catalyst. For biomass valorization particular attention will be given to catalytic testing performed in continuous modes as this allows for the clear evaluation of the catalyst stability.

\section{High Temperature Alkane Conversion}

\subsection{Conversion of Light Alkanes}

The main current types of dehydrogenation catalysts are not based on zeolites but require either metallic platinum (Oleflex Process) or chromium oxide supported catalysts (Catofin Process), both working in the presence of promoters. ${ }^{[27]}$ The deactivation of platinum-supported catalysts occurs primarily due to the agglomeration and sintering of platinum and the poisoning of active sites by coke. The addition of $\mathrm{Sn}$ as a promoter has been found to confer several beneficial geometric and electronic properties to $\mathrm{Pt}$, such as improving the particle dispersion, as well as reducing the acidity of the support, suppressing side reactions, and the transfer of coke from the Pt active sites to the support. ${ }^{\text {[27a] }}$ Similar to Pt-based catalysts, chromia-based catalysts deactivate due to the formation of coke and the sintering of the chromia active sites. ${ }^{[28]}$ However, upon regeneration, irreversible deactivation occurs due to the sintering of alumina that reduces the available surface area required to stabilize $\mathrm{Cr}^{6+}$ species, the incorporation of chromium species into the alumina framework, and the phase transition of $\gamma$ - to $\theta$ - or even $\alpha$-alumina at high temperatures. ${ }^{[27 a]}$ Strategies to restrict the phase transformation of $y$ - to $\alpha$-alumina have involved the doping of the support with metal oxides. ${ }^{[29]}$ Zeolites-based dehydrogenation catalysts have so far failed due to a lack of regenerability of the metal phase introduced mainly by ion-exchange or impregnation and located in extra-framework positions.

However, the use of zeolites as metal supports is an efficient way to obtain catalysts with highly dispersed metal species. ${ }^{[30]}$ The dispersion and stabilization of the metal is facilitated by confinement within the zeolite pore system and its interaction with the zeolite surface, reducing its migration and sintering. Metalcontaining zeolites prepared by conventional ionexchange/impregnation procedures have been investigated for the dehydrogenation of light alkanes, but are susceptible to sintering of the metal species. ${ }^{[31]}$ In addition, impregnation and ion exchange procedures do not always allow for careful control of the location of the metal on the support, resulting in catalysts with poor metal distribution and metal particles located mainly on the external surface of the catalyst. ${ }^{[30-31]}$

Several recent strategies for improving the resistance to migration and sintering of the metal phase of metal-containing zeolites for propane conversion are highlighted (Table 1), including examples of zeolites containing extra-framework metal species only, extra-framework metal species prepared from framework metal precursors, and zeolites containing both framework and extra-framework metal species.

Corma et al. have developed an innovative approach for the preparation of subnanometric platinum species with high thermal stability in the cages, cups, and channels of zeolites. ${ }^{[32]}$ The novel materials were tested for propane dehydrogenation (PDH) in a fixed-bed reactor at $550-600{ }^{\circ} \mathrm{C}$ and in several oxidationreduction cycles at $650-700{ }^{\circ} \mathrm{C}$, and were compared with Ptcontaining zeolite catalysts prepared by wet impregnation, vide infra.

Liu et al. achieved the preparation of subnanometric platinum (atomic Pt and Pt clusters) during transformation of a purely siliceous layered MCM-22 precursor to MCM-22 zeolite. ${ }^{[32 a]}$ The Pt subnanometric species were introduced during the swelling of the lamellar MCM-22 precursor using an organic surfactant. Calcination of the precursor resulted in the encapsulation of the $\mathrm{Pt}$ species in the supercages and exterior cups. The reaction rate of the Pt species of the novel material was approximately 1.7 times higher than that of wet-impregnated material and demonstrated greater stability over multiple cycles. Oxidationreduction cycles at $650^{\circ} \mathrm{C}$ revealed that the $\mathrm{Pt}$ atoms and small $\mathrm{Pt}$ clusters were susceptible to aggregation, however, the size distribution of most of the Pt nanoparticles remained below $2 \mathrm{~nm}$. Ultimately the procedure does not fully prevent the aggregation of the metal species but significantly improves their stability in comparison to the wet-impregnated material consisting of metal aggregates between 30 to $50 \mathrm{~nm}$.

Another approach reported by Liu et al. involved the one-pot 
synthesis of $\mathrm{Pt}$ and $\mathrm{PtSn}$ clusters stabilized by the presence of $\mathrm{K}^{+}$ in siliceous MFI zeolite confirmed by HAADF-HRSTEM. ${ }^{[32 b]}$ The initial Pt@MFI and PtSn@MFI materials were prone to fast deactivation and sintering, however, the introduction of a controlled amount of $\mathrm{K}^{+}$allowed for the preparation of subnanometric Pt clusters having a size ranging from 0.4 to 0.7 $\mathrm{nm}$. The preferential location of the metal clusters in the sinusoidal channels of the MFI framework was attributed to the presence of template molecules at the intersectional voids and the greater volume of the sinusoidal compared to the straight channels. These materials (containing either Pt or PtSn clusters synthesized in the presence of $\mathrm{K}^{+}$) possessed significantly improved stability, attributed to the stabilizing effect of $\mathrm{K}^{+}$. The K-PtSn@MFI catalyst demonstrated an initial propane conversion rate of approximately $70 \%$ that decreased to approximately $50 \%$ after $70 \mathrm{~h}$ of operation, and a high selectivity to propylene $(>90 \%)$. The high catalytic performance was confirmed by three cycles of reactionregeneration. The stability of the subnanometric PtSn clusters was demonstrated up to $700{ }^{\circ} \mathrm{C}$ after two oxidation-reduction cycles confirmed by HAADF-HRSTEM.

For zeolites containing both framework and extra-framework metal species, Wang et al. and Xu et al. independently reported on the use of zeolite BEA containing framework $\mathrm{Sn}$ to stabilize $\mathrm{Pt}$ species for $\mathrm{PDH} .{ }^{[33]}$ Both reports begin with a similar synthetic strategy by dealumination of the zeolite BEA followed by different techniques for the incorporation of $\mathrm{Sn}$ atoms into the framework and the loading of Pt. Both studies reported the framework Sn sites facilitate the high dispersion of the Pt species. Wang et al. ${ }^{[33 a]}$ reported their optimized catalyst $(0.3 \mathrm{wt} \% \mathrm{Pt}, 0.5 \mathrm{wt} \% \mathrm{Sn})$ lost only $13 \%$ of its initial propene formation rate over $12 \mathrm{~h}$ at $600{ }^{\circ} \mathrm{C}$ and that it was stable over four reaction cycles at $550{ }^{\circ} \mathrm{C}$ with > $99 \%$ selectivity to propylene. After reaction at $550{ }^{\circ} \mathrm{C}(5 \mathrm{~h}), \mathrm{Pt}$ particles $\approx 1.6 \mathrm{~nm}$ could be observed indicating that not all of the Pt was stabilized, however, the size of the particles did not significantly increase after further reaction (12 h). TG analysis of the spent catalyst showed a weight loss of $0.6 \%$ indicating low coke formation. The healing of silanol defects was confirmed by FTIR spectroscopy, and the incorporation of $\mathrm{Sn}$ into the framework was investigated by XRD, diffuse reflectance UV/Vis spectroscopy and XPS. The stable activity and high selectivity to propylene of the catalyst was attributed to the strong interaction between the Pt clusters and framework Sn sites.

$\mathrm{Xu}$ et al ${ }^{[33 \mathrm{~b}]}$ reported their optimized catalyst $(0.5 \mathrm{wt} \% \mathrm{Pt}, 1.0$ wt $\% \mathrm{Sn}$ ) demonstrated $50 \%$ conversion at the beginning of the reaction, decreasing to $45 \%$ over $48 \mathrm{~h}$ at $570{ }^{\circ} \mathrm{C}$. The catalyst displayed consistent activity over two reaction cycles with up to $98 \%$ selectivity to propylene and low coke formation ( $2 \%$, TGA). The $\mathrm{Pt}$ species were determined to be part of bimetallic $\mathrm{Pt} / \mathrm{Sn}$ particles (average diameter of $1.26 \mathrm{~nm}$ ) located on the surface of the zeolite at framework $\mathrm{Sn}$ sites. The incorporation of $\mathrm{Sn}$ into the framework was studied, and the high dispersion of the $\mathrm{Sn}$ and $\mathrm{Pt}$ species was attributed to the absence of reflections for $\mathrm{SnO}_{2}$ and $\mathrm{Pt}^{0}$ in the XRD patterns. The chemical speciation of $\mathrm{Sn}$ from XPS measurements was reported as framework Sn(IV) coordinated to four Si-O-Si linkages, framework Sn(II) coordinated to two Si-O$\mathrm{Si}$ linkages that interfaces with the Pt particle, and metallic Sn incorporated in the bimetallic $\mathrm{Pt} / \mathrm{Sn}$ particles.

Attempts to employ zeolites containing first row transition metals for PDH have involved the preparation of cobalt confined in zeolite Beta. Adopting a procedure from Baran et al. ${ }^{[34]}$ Chen et al. ${ }^{[35]}$ dealuminated zeolite Beta in nitric acid to form T-atom vacancies, followed by mixing with a solution of cobalt(II) nitrate, and calcination at $600{ }^{\circ} \mathrm{C}$. Calcination of the cobalt-loaded dealuminated zeolite Beta was inferred to extract framework $\mathrm{Co}^{2+}$ to form extra-framework $\mathrm{CoO}_{x}$ species. The high dispersion of the $\mathrm{CoO}_{x}$ species was attributed to presence of silanols created at Tatom vacancies. The best performing catalyst, with a $0.5 \mathrm{wt} \%$ Co loading, displayed a maximum propane conversion of $53 \%$, plateauing to $40 \%$ after $6 \mathrm{~h}$, and a selectivity to propylene $>98 \%$. Regeneration of the catalyst at $600^{\circ} \mathrm{C}$ for $2 \mathrm{~h}$ in air demonstrated consistent activity over three reaction cycles of $6 \mathrm{~h}$ before discernable deactivation during the fourth cycle. The similar activity between the calcined only and reduced samples was attributed to the reduction of $\mathrm{CoO}_{x}$ species to metallic Co during the dehydrogenation reaction.

Similar to their work on Co-BEA, Chen et al. attempted to prepare vanadium containing-BEA zeolites $(0.5-10 \mathrm{wt} \% \mathrm{~V})$ by post-synthetic dealumination and treatment with $\mathrm{NH}_{4} \mathrm{VO}_{3}$ solution. ${ }^{[36]}$ Characterization of the catalysts indicated the formation of extra framework polymeric vanadium species, in particular for high loadings ( $>3 \mathrm{wt} \%$ ). Catalysts with a low $\mathrm{V}$ loading $(\leq 3 \mathrm{wt} \%$ ) were claimed to possess monomeric and isolated V species bound to the zeolite framework, however, their exact nature was not determined. The catalysts were tested for $\mathrm{PDH}$ at $600{ }^{\circ} \mathrm{C}$ with the higher loaded catalysts ( $\geq 3 \mathrm{wt} \% \mathrm{~V}$ ) showing similar activity; the activity dropped initially from approximately $40 \%$ conversion to $23 \%$ after $6 \mathrm{~h}$, and a maximum propylene selectivity of $95 \%$ was observed. Higher $\mathrm{V}$ loadings were also attributed to higher coke formation due to the greater acidity of the catalyst. The stability of the catalyst was evaluated by regeneration every $2 \mathrm{~h}$ after $4 \mathrm{~h}$ on stream for a total of $16 \mathrm{~h}$ of operation demonstrating consistent behavior. Earlier work by Chalupka et al. and Trejda et al. on V-SiBEA (0.25-4.00 wt\% V) prepared by a similar post-synthetic procedure observed that either framework or both framework and extra framework $\mathrm{V}^{5+}$ species were formed depending on the $\mathrm{NH}_{4} \mathrm{VO}_{3}$ concentration and $\mathrm{pH}$ of the solution. ${ }^{[37]}$

In addition to cobalt and vanadium, the catalytic properties of framework and extra-framework iron-containing BEA and MFI type zeolites for monomolecular PDH were investigated by Yun and Lobo. ${ }^{[38]}$ Determination of $\mathrm{Fe}^{3+}$ in the MFI framework by XRD and diffuse reflectance UV/Vis revealed that after calcination at $480{ }^{\circ} \mathrm{C}$ a large fraction of the framework $\mathrm{Fe}^{3+}$ was retained, however, treatment with steaming at $700{ }^{\circ} \mathrm{C}$ resulted in the majority of $\mathrm{Fe}^{3+}$ migrating to extra-framework positions. With a propane feed of $5 \mathrm{~mol} \%$ the calcined H-[Fe]ZSM- 5 sample displayed a greater rate of dehydrogenation by a factor of 2.7 and 3.8 compared to the H-[Al]ZSM-5 and steamed H-[Fe]ZSM-5 respectively, and a higher relative rate of dehydrogenation to cracking compared to $\mathrm{H}-[\mathrm{AI}] \mathrm{ZSM}-5$ (22 vs 0.36 ) at $530{ }^{\circ} \mathrm{C}$. Comparison of the turnover frequencies (TOF) between the calcined Fe-MFI and Fe-BEA samples showed a negligible difference. The results indicate that the conversion of propane occurs mainly on the isolated framework Fe sites, compared to the extra-framework Fe sites, and that the zeolite pore size is not an important factor in the propane dehydrogenation reaction. However, with a higher propane feed $(16 \mathrm{~mol} \%)$ at $530{ }^{\circ} \mathrm{C}$ the conversion of the $\mathrm{H}$-[Fe]ZSM- 5 sample $(7.2 \%)$ was lower than the $\mathrm{H}-[\mathrm{Al}] Z \mathrm{SM}-5$ sample $(18.7 \%)$, but the selectivity was higher (78 vs $20 \%$ ). In addition, based on the change of the unit cell volume, approximately $50 \%$ of the $\mathrm{Fe}$ migrated to extra-framework positions during the reaction. Information concerning the 
recyclability and catalyst stability over extended time periods was not reported.

Zeolites containing framework gallium have been studied for several decades due to their ability to dehydroaromatize propane and other light alkanes, and have been used as catalysts in the petrochemical industry since the mid-1980s in the joint UOP and BP Cyclar Process. ${ }^{[39]}$ The majority of investigations have been focused on maximizing the selectivity to aromatics while only a small number of investigations have discussed PDH, the first step of aromatization, typically reporting low selectivity and stability. ${ }^{[40]}$

Choi et al. investigated PDH over gallosilicate MFI obtained by direct synthesis in the presence of (3Mercaptopropyl)trimethoxysilane (MPS). ${ }^{[40 \mathrm{~b}]}$ It was proposed that Si species of MPS are incorporated into the zeolite framework after hydrolysis of the trimethoxy groups. Simultaneously, the thiol group on the preserved Si-mercaptopropyl linkage interacts with the metallic ions facilitating the incorporation of metals into the zeolite pore structure during the crystallization step. The MPS was removed by calcination at $550{ }^{\circ} \mathrm{C}$ and it was hypothesized that, based on temperature-programmed desorption (TPD) data, extraframework $\mathrm{Ga}$ species were formed in addition to framework $\mathrm{Ga}$ sites. It was observed that this synthetic approach allows for the preparation of gallosilicate MFI with a relatively higher concentration of strong Lewis acid sites and a reduced concentration of Brønsted acid sites. The catalytic evaluation of the MPS-gallosilicate MFI catalyst at $600{ }^{\circ} \mathrm{C}$ showed a significant increase in the selectivity to propylene compared with non-MPS gallosilicate MFI. The MPS-gallosilicate MFI catalyst was also compared with a prototypical chromia-alumina catalyst at $600{ }^{\circ} \mathrm{C}$ for $12 \mathrm{~h}$. The MPS-gallosilicate MFI materials demonstrated a lower rate of deactivation and higher propylene yield, but a lower selectivity to propylene compared to the chromia-alumina catalyst ( $75 \%$ vs $85 \%$ ). However, at higher levels of conversion the selectivity to propylene was reported to be higher than earlier reports in the literature for gallosilicates under similar conditions. This was attributed to the relatively lower number of Brønsted acid sites which are believed to be active for the oligomerization and cyclization steps of alkane aromatization.

Recently, Nakai et al. investigated high-silica Ga-BEA prepared by dry gel (DGC) conversion method for $\mathrm{PDH}$ at $650^{\circ} \mathrm{C}$, and compared it with Ga-BEA prepared by dealumination/wet impregnation and Ga-MFI. ${ }^{[41]}$ The DGC Ga-BEA showed superior performance in terms of propane conversion $(54.3 \%$ at $15 \mathrm{~min})$ and propylene yield $(31.5 \%$ at $15 \mathrm{~min})$ compared to the other catalysts, however, the propane conversion and propylene yield decreased to $\approx 35 \%$ and $\approx 25 \%$ respectively, after $6 \mathrm{~h}$ on stream. It was observed that the Ga-BEA catalyst with a higher $\mathrm{Si} / \mathrm{G}$ a ratio demonstrated a higher conversion of propane, higher yield of propylene, and lower formation of coke compared to the equivalent catalyst with a lower $\mathrm{Si} / \mathrm{Ga}$ ratio. The superior performance of the Ga-BEA with a higher $\mathrm{Si} / \mathrm{Ga}$ ratio was attributed to the relatively lower number of Brønsted acid sites and higher mesoporosity of the catalyst resulting in a lower amount of coke formation and higher diffusion of the reactant and products. However, information concerning the recyclability and catalyst stability was not presented.

From these examples it appears that the incorporation of an isolated metal species into the zeolite framework can be an effective strategy to obtain a catalyst whose active metal species have improved resistance to sintering, such as the stabilization of $\mathrm{Pt}$ on Sn-BEA. However, some metals appear to be relatively less stable when incorporated into the zeolite framework resulting in the formation of extra-framework species, and changes in the catalytic behavior of the material are observed. Alternatively, the transformation of metals located at T-sites during calcination can result in the formation of extra-framework species with high dispersion, while optimizing the ratio between Brønsted and Lewis acid sites can have significant effects on the catalyst performance (Figure 2).

\subsection{Fluid Catalytic Cracking}

One of the most interesting examples of metal containing zeolites operating outside the comfort zone is zeolite $Y$ stabilized by rareearth (RE) metal ions for fluid catalytic cracking (FCC). FCC is a mature petrochemical process and the literature contains a broad range of investigations including FCC catalyst synthesis, testing and deactivation. For further details on various aspects of FCC the reader is directed to a number of excellent reviews. ${ }^{[16 a, 42]}$ Despite the commercial employment of FCC for almost 80 years the technology is still facing the several challenges related to changes in the types of available feedstocks including nonconventional biomass-derived feeds, naphtha feeds and FischerTropsch waxes. ${ }^{[42 b, 43]}$ FCC catalysts typically operate around $500{ }^{\circ} \mathrm{C}$ in the reactor, i.e. within the "comfort zone", but are exposed to up to $800{ }^{\circ} \mathrm{C}$ in the regenerator, i.e. outside the "comfort zone". ${ }^{[42 a]}$ Under such harsh conditions, including in the presence of steam during regeneration, the catalyst performance is strongly affected and dealumination of the zeolite becomes a significant problem. In addition to hydrothermal deactivation, FCC catalyst suffers from irreversible deactivation due to the presence of metal impurities in the feed. ${ }^{[42 a, 42 c]}$ Depending on the quality of the heavy fraction, the FCC feed may contain different amounts of metals such as $\mathrm{Ni}, \mathrm{Fe}$ and $\mathrm{V}$. They are prodcued when porphyrins decompose at high temperature and deposit on the catalyst surface, damage the zeolite structure, and favor dehydrogenation reactions that increase coke formation. The most common and detrimental metal-contaminant is $\mathrm{V}$, which in addition to the aforementioned issues, in the presence of steam facilitates the loss of the catalyst surface area, loss of acid sites, and dealumination; a similar issue experienced by Mo/H-ZSM-5 during methane dehydroaromatization, vide infra section 2.3. Furthermore, $\mathrm{V}$ interacts with RE metal ions to generate lowmelting point RE vanadates which destabilize the zeolite structure. ${ }^{[44]}$

FCC catalysts are typically composed of (1) an active zeolite component (FAU structure with various levels of ultra-stabilization, the so-called US-Y), ion-exchanged with ammonium and/or RE salts, followed by calcination, (2) active matrix (alumina), (3) filler (clay), and (4) a binder (alumina and/or silica). ${ }^{[22 c, 45]}$

The introduction of $\mathrm{RE}$ metal ions $\left(\mathrm{La}^{3+}, \mathrm{Ce}^{3+}, \mathrm{Sm}^{3+}, \mathrm{Gd}^{3+}\right.$, $\left.\mathrm{Dy}^{3+}\right)$ improves the stability and activity of the zeolite catalyst by reducing the loss of aluminum and by the promotion of the catalytic isomerization, cracking and alkylation of alkanes. ${ }^{[46]} \mathrm{A}$ large number of investigations have been devoted to determining the coordination environment and effect of RE metal ions within zeolite $Y$. In the '70s and ' 80 s it was recognized that $Y$ zeolites 


\section{WILEY-VCH}

Table 1. Examples of metal-containing zeolites operating outside the "comfort zone" of current heterogeneous catalytic reactions: propane dehydrogenation (PDH) and methane dehydroaromatization (MDA).

\begin{tabular}{|c|c|c|c|c|c|c|c|c|}
\hline Entry & Catalyst & $\begin{array}{l}\text { Metal State } \\
\text { (as synthesized) })^{[a]}\end{array}$ & Synthesis Procedure & Reaction & Reaction Conditions & Performance $^{[b]}$ & $\begin{array}{l}\text { Identified } \\
\text { Deactivation } \\
\text { Pathway }\end{array}$ & Ref. \\
\hline 1 & $\begin{array}{l}\mathrm{Pt} @ M C M-22 \\
(0.11 \mathrm{wt} \% \mathrm{Pt})\end{array}$ & EFW & $\begin{array}{l}\text { Pt introduction during } \\
\text { swelling process of } \\
\text { lamellar zeolite } \\
\text { precursor }\end{array}$ & $\mathrm{PDH}$ & $\begin{array}{l}550^{\circ} \mathrm{C}, 1 \mathrm{bar}, \\
W H S V=3.2 \mathrm{~h}^{-1}\end{array}$ & $\begin{array}{l}\text { Reaction rate: } 0.6 \mathrm{mmol} \mathrm{s}^{-1} \mathrm{~g}^{-1} \\
5 \text { reaction-regeneration cycles }\end{array}$ & Sintering, coke & [32a] \\
\hline 2 & $\begin{array}{l}\text { K-PtSn/MFI } \\
(0.45 \text { wt } \% \text { Pt, } 0.90 w t \% \\
\text { Sn, } 0.65 \text { wt } \% \text { K) }\end{array}$ & EFW (Pt clusters) & $\begin{array}{l}\text { One-pot synthesis in } \\
\text { alkaline media }\end{array}$ & $\mathrm{PDH}$ & $\begin{array}{l}600^{\circ} \mathrm{C}, 1 \mathrm{bar} \\
\text { WHSV }=1.8 \mathrm{~h}^{-1}\end{array}$ & $\begin{array}{l}27 \mathrm{~s}^{-1} \text { and } 17 \mathrm{~s}^{-1} \text { initial TOF } \\
\text { Reaction rate: } \sim 80 \mathrm{mmol} \mathrm{s}^{-1} \mathrm{~g}^{-1} \\
3 \text { reaction-regeneration cycles }\end{array}$ & Coke & [32b] \\
\hline 3 & $\begin{array}{l}0.3 \mathrm{Pt} / 0.5 \mathrm{Sn}-\mathrm{Si}-\text { Beta } \\
(0.26 \mathrm{wt} \% \mathrm{Pt}, \\
0.47 \mathrm{wt} \% \mathrm{Sn})\end{array}$ & $F W S n+E F W P t$ & $\begin{array}{l}\text { Impregnation of } \\
\text { dealuminated BEA } \\
\text { zeolite }\end{array}$ & PDH & $\begin{array}{l}500-600^{\circ} \mathrm{C}, 1 \mathrm{bar}, \\
W H S V=1 \mathrm{~h}^{-1}\end{array}$ & $\begin{array}{l}4.6 \mathrm{~min}^{-1} \text { initial TOF, propylene formation rate } 2.3 \mathrm{~mol} \\
\mathrm{~g}^{-1} \mathrm{~h}^{-1}\left(550^{\circ} \mathrm{C}\right), 3.1 \mathrm{~mol} \mathrm{~g}^{-1} \mathrm{~h}^{-1}\left(600^{\circ} \mathrm{C}\right) \\
\text { Deactivation rate: } 0.007 \mathrm{~h}^{-1}\left(550^{\circ} \mathrm{C}\right) \\
4 \text { reaction-regeneration cycles }\end{array}$ & Coke & [33a] \\
\hline 4 & $\begin{array}{l}\mathrm{Pt} / \mathrm{Sn} 2.00-\mathrm{Beta} \\
(\mathrm{Si} / \mathrm{Al}=440 ; \mathrm{Sn} / \mathrm{Pt}= \\
2.00 ; 0.5 \mathrm{wt} \% \mathrm{Pt})\end{array}$ & $\begin{array}{l}\text { PtSn alloys (EFW) } \\
\text { attached to FW Sn }\end{array}$ & $\begin{array}{l}\text { Post-synthetic } \\
\text { incorporation of Sn in } \\
\text { BEA framework } \\
\text { followed by Pt } \\
\text { introduction }\end{array}$ & $\mathrm{PDH}$ & $0^{\circ} \mathrm{C}, \mathrm{WHSV}=2400 \mathrm{~h}^{-1}$ & $\begin{array}{l}114 \mathrm{~s}^{-1} \mathrm{TOF} \\
\text { Deactivation rate: } 0.0063 \mathrm{~h}^{-1} \\
2 \text { reaction-regeneration cycles }\end{array}$ & Coke & [33b] \\
\hline 5 & $\begin{array}{l}0.5 \text { CoSiBeta } \\
(0.5 \mathrm{wt} \% \mathrm{Co})\end{array}$ & EFW & $\begin{array}{l}\text { Impregnation of } \\
\text { dealuminated BEA } \\
\text { zeolite }\end{array}$ & - & $\begin{array}{l}550-600^{\circ} \mathrm{C}, 1 \mathrm{bar}, \\
W H S V=0.4 \mathrm{~h}^{-1}\end{array}$ & $\begin{array}{l}32.9 \mathrm{~h}^{-1} \text { TOF }\left(550^{\circ} \mathrm{C}\right) \text {, } \\
\text { Deactivation rate: } 21.1 \%\left(600^{\circ} \mathrm{C}\right)^{[\mathrm{e}]} \\
4 \text { reaction-regeneration cycles }\end{array}$ & Coke & [35] \\
\hline 6 & $\begin{array}{l}\text { V-Beta } \\
(3 \mathrm{wt} \% \mathrm{~V})\end{array}$ & $F W+E F W$ & Impregnation & $\mathrm{PDH}$ & $\begin{array}{l}600^{\circ} \mathrm{C}, 1 \mathrm{bar}, \\
W H S V=0.6 \mathrm{~h}^{-1}\end{array}$ & $\begin{array}{l}0.02 \mathrm{~s}^{-1} \text { initial, TOFs and } 0.01 \mathrm{~s}^{-1} \text { final TOF } \\
\text { Deactivation rate: } \sim 12.5 \% \\
4 \text { reaction-regeneration cycles }\end{array}$ & Coke & [36] \\
\hline 7 & $\begin{array}{l}\mathrm{H}-[\mathrm{Fe}] Z \mathrm{SM}-5 \\
(\mathrm{Si} / \mathrm{Fe}=26,48) \\
\text { Fe-BEA } \\
(\mathrm{Si} / \mathrm{Fe}=15)\end{array}$ & $F W+$ minor $E F W$ & $\begin{array}{l}\text { Direct isomorphous } \\
\text { substitution in alkaline } \\
\text { media }\end{array}$ & PDH & $\begin{array}{l}460-530^{\circ} \mathrm{C}, 1 \mathrm{bar}, \\
\mathrm{WHSV}=1.8 \mathrm{~h}^{-1} \text { for experiments } \\
\text { with low conversion (TOF and } \\
\text { reaction rates) }\end{array}$ & $\begin{array}{l}\text { TOF of dehydrogenation, } \mathrm{mol} \mathrm{s}^{-1}\left(\mathrm{~mol} \mathrm{H}^{+}\right)^{-1} \times 10^{4} \text { for } \mathrm{H}- \\
\text { [Fe]beta(15) } 5.97\left(550^{\circ} \mathrm{C}\right)\end{array}$ & $\begin{array}{l}\text { Coke, } \\
\text { demetallation }\end{array}$ & [38] \\
\hline 8 & $\begin{array}{l}\text { Ga-Beta } \\
(\mathrm{Si} / \mathrm{Ga}=35)\end{array}$ & $F W+E F W$ & $\begin{array}{l}\text { Direct isomorphous } \\
\text { substitution in alkaline } \\
\text { media }\end{array}$ & $\mathrm{PDH}$ & $\begin{array}{l}600^{\circ} \mathrm{C}, 1 \mathrm{bar} \text {, } \\
\text { the amounts of each catalyst } \\
\text { were adjusted for a similar }\end{array}$ & $\begin{array}{l}\text { TOFs }^{[]]} \\
\sim 120-70(5 \mathrm{~h}) \mathrm{mmol} \mathrm{h}^{-1} \mathrm{~mol}^{-1} \\
\sim 45-30(5 \mathrm{~h}) \mathrm{mmol} \mathrm{h}^{-1} \mathrm{~mol}^{-1}\end{array}$ & Coke & [40b] \\
\hline
\end{tabular}




\section{WILEY-VCH \\ $\mathrm{H}$}

Ga-Beta-200 (Si/Ga =

177.7)

Direct isomorphous

substitution in alkaline $\quad$ PDH

media

Impregnation

Mo/HZSM-5

$(\mathrm{Si} / \mathrm{Al}=30 ; 2 \mathrm{wt} \% \mathrm{Mo})$

EFW

Impregnation

MDA

Impregnation

MDA

$(\mathrm{Si} / \mathrm{Al}=20 ; 6 \mathrm{wt} \% \mathrm{Mo})$

EFW

Mo/H-ZSM-5

12

$(\mathrm{Si} / \mathrm{Al}=15 ; 5 \mathrm{wt} \% \mathrm{Mo})$
EFW

Impregnation conversion level ( 7\%). $5 \%$

$\mathrm{C}_{3} \mathrm{H}_{8}$ in $\mathrm{N}_{2}, 20 \mathrm{~cm}^{3} \mathrm{~min}^{-1}$.

$650{ }^{\circ} \mathrm{C}, 1 \mathrm{bar}, 10 \mathrm{~mol} \% \mathrm{C}_{3} \mathrm{H}_{8} /$

$90 \% \mathrm{He}, 6.69 \mathrm{~cm}^{3} \mathrm{~min}^{-1}$, the

amount of the catalyst was not

provided.

Reaction: $700^{\circ} \mathrm{C}, 1 \mathrm{bar}$

WHSV $0.8 \mathrm{~h}^{-1}$.

$>50 \%$ of initial $Y$ of benzene over 100 reactionregeneration cycles

Regeneration: $700^{\circ} \mathrm{C}$, air

WHSV $3.9 \mathrm{~h}^{-1}, 7 \mathrm{~h}$.

Benzene formation rates approximately the same after

Coke,

Regeneration: $450^{\circ} \mathrm{C}$, air (SV

8 reaction-regeneration cycles

dealumination

$1 / 50 \mathrm{vol} / \mathrm{vol}$ ).

Coke,

Reaction: $700^{\circ} \mathrm{C}, 1 \mathrm{bar}$

Methane conversion and benzene yield constant over

sintering at high

temperature and

Mo loading,

dealumination

[a] $\mathrm{FW}=$ Framework metal sites, EFW = Extra-framework metal sites.

${ }^{[b]} \mathrm{X}, \mathrm{S}, \mathrm{Y}-$ Propane conversion, selectivity to propylene, and yield of propylene; TOF - turnover frequency; $\mathrm{T}-$ time required for rates to decrease by a factor of $e^{-1}$.

${ }^{[c]}$ The reaction rates were measured when the conversion of propane is lower than $10 \%$ and the values have been normalized to the amount of $\mathrm{Pt}$ in the catalysts.

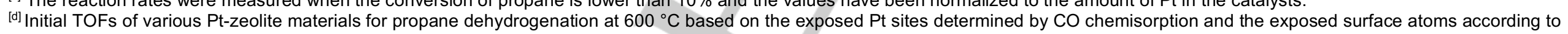

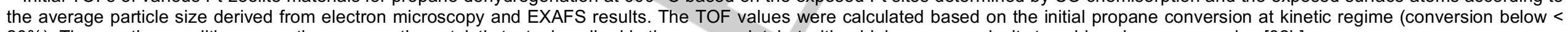
$20 \%$ ). The reaction conditions were the same as the catalytic tests described in the manuscript, but with a higher space velocity to achieve lower conversion [32b].

[e] Deactivation rate relative to the maximum propane conversion at $6 \mathrm{~h}$ on stream.

[f] TOFs were calculated based on the Brønsted acid site or the total acid site concentrations. 
with a greater lanthanum content experienced dealumination to a lesser degree during steaming, and that during the calcination of exchanged zeolite $Y$ the reduced water content allows $\mathrm{La}^{3+}$ cations to migrate into the sodalite cages. ${ }^{[47]}$ Later, van Bockhoven et al. observed that $\mathrm{La}^{3+}$ cations induce a polarization of the framework Al resulting in an increase of the $\mathrm{Si}-\mathrm{O}-\mathrm{Al}$ and $\mathrm{Si}-\mathrm{O}-\mathrm{Si}$ angles and the unit cell parameter. ${ }^{[48]}$ Furthermore, several recent studies have described a strengthening of the $\mathrm{Al}-\mathrm{O}$ bond owing to an increase in the positive charge near the $\mathrm{Al}$ atom due to the polarization effect of $\left[R E(O H)_{n}\right]^{(3-n)+}(n=1,2)$ and $R^{3+}$ from dehydration of $\mathrm{RE}\left(\mathrm{H}_{2} \mathrm{O}\right)_{n}{ }^{3+} \cdot{ }^{[49]}$

From experimental and computational methods, Schüßler et al. reported that for both high $(\mathrm{Si} / \mathrm{Al}=4)$ and low $(\mathrm{Si} / \mathrm{Al}=1.2)$ silica faujasite the majority of $\mathrm{La}^{3+}$ cations are located within the sodalite cages as multinuclear $\mathrm{OH}$-bridged cationic species while a relatively smaller amount of mononuclear $\mathrm{La}^{3+}$ species were located in the supercages. However, for the low silica faujasite, the more negative Al-rich framework improved the stability of bare $\mathrm{La}^{3+}$ species located in the supercage. ${ }^{[50]}$ More recently, Zhang et al. proposed that multi-core RE bridging structures that have a greater oxygen content are responsible for the stabilisation of the zeolite by RE metal ions. ${ }^{[51]}$ Using quantum mechanical calculations, Louwen et al. reported that the improved stability of zeolite $\mathrm{Y}(\mathrm{Si} / \mathrm{Al}=3)$ upon the introduction of $\mathrm{La}^{3+}$ can be attributed to the increase in the energy barrier of dealumination. ${ }^{[14]}$ Overall, the literature concerning the introduction of RE metal ions into faujasite suggests an increase in the stability of Al under harsh conditions. Improved understanding of the nature of RE species and their electronic interaction with the zeolite framework over the last decade will serve to guide future advancements in catalyst stability under harsh conditions (Figure 2). In particular, the improved stability of the zeolite framework conferred by particular metals provides new research opportunities for FCC catalysts and the next generation of naphtha conversion catalysts as refiners will increasingly need to consider the direct conversion of crude to chemicals. ${ }^{[52]}$

\subsection{Non-Oxidative Conversion of Methane}

The non-oxidative conversion of methane, such as methane dehydroaromatization (MDA), is an attractive reaction for the production of $\mathrm{H}_{2}$ and chemicals, however, an evaluation of the reaction thermodynamics shows that the production of aromatic is unfavorable below $700{ }^{\circ} \mathrm{C}$ and the reaction is highly endothermic. The reaction is therefore significantly hindered by low substrate conversion, poor product selectivity, and catalyst deactivation due to the formation of coke. ${ }^{[53]}$ While the formation of coke can be treated with an optimized reaction-regeneration cycle, irreversible deactivation of the catalyst continues to occur over extended time periods. ${ }^{[6,54]}$ Alternatively, the reaction temperature can be increased to favor the formation of aromatic products, however this results in severe coke formation and catalyst instability. ${ }^{[55]}$

Under conventional MDA operating conditions, the typical Mo containing catalyst, obtained by impregnation on HZSM-5, deactivates due to the formation of a carbonaceous layer consisting of polyaromatic hydrocarbons at the external surface. This decreases the accessibility of the Brønsted acid sites in the zeolite micropores, restricts the access of molecules to the acid sites, and facilities the sintering of molybdenum carbide species due to weak interactions with the zeolite surface. ${ }^{[8 a]}$ In addition, excessive heat treatment and the presence of water during the reaction, especially during the regeneration step, results in the dealumination of the zeolite. Under such conditions the Mo species become mobile and react with framework Al to form aluminum molybdates. ${ }^{[6,56]}$ The degree of dealumination is strongly influenced by the Mo content and Si/Al ratio. ${ }^{[6,57]}$ These new Mo species cannot form carbides, resulting in irreversible

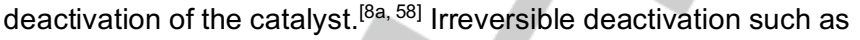
this prevents continuous recycling of the catalyst which is crucial due to the rapid formation of coke. Several strategies have been proposed to improve the stability of the catalyst during regeneration and to adapt metal-containing zeolites to harsh regeneration conditions (Table 1$){ }^{[6,59]}$

Kosinov et al. investigated the structural and textural stability of HZSM-5 with different loadings of Mo in air at high temperature $\left(550-700{ }^{\circ} \mathrm{C}\right) .{ }^{[6]}$ It was observed that high Mo loading lead to the formation of aluminum molybdate and irreversible damage to the zeolite framework during metal dispersion into the micropores when calcined above $550{ }^{\circ} \mathrm{C}$. In comparison, low Mo loading (1$2 \%$ ) significantly improved the oxidative stability of the catalyst. Mo species were predominantly located in the zeolite micropores as cationic mono- and di-nuclear Mo-oxo complexes, even at high calcinations temperature. At $2 \mathrm{wt} \%$ Mo loading the catalyst retained more than $50 \%$ of its initial activity after 100 reactionregeneration cycles and demonstrated a substantially improved total aromatics yield. Another strategy to improve the stability of the catalyst has been to employ less harsh regeneration procedures. Ma et al. demonstrated the ability to remove carbon deposits by using $2 \% \mathrm{NO}$ as a promoter in air. ${ }^{[59 a]}$ The removal of coke began at $330{ }^{\circ} \mathrm{C}$ and complete removal was achieved at $450^{\circ} \mathrm{C}$, suppressing the migration and sublimation of Mo species and minimizing damage to the structure as confirmed by 8 reaction-regeneration cycles. Han et al. investigated the use of either oxidative or reductive regeneration treatments on $\mathrm{Mo} / \mathrm{H}$ ZSM-5 catalysts with different Mo loading (1-7 wt\%). ${ }^{[59 b]}$ It was observed for the optimized catalyst (5 wt $\% \mathrm{Mo}$ ) that oxidative regeneration at $450{ }^{\circ} \mathrm{C}$ was the most effective treatment attributed to the removal of Mo-associated graphite coke. Higher regeneration temperatures of up to $850{ }^{\circ} \mathrm{C}$ caused irreversible deactivation due to the sublimation of $\mathrm{MoO}_{3}$ and the loss of Brønsted acidity. It was concluded that the selective recovery of Brønsted acid sites near Mo sites, rather than isolated acid sites, is sufficient to restore the catalytic activity in terms of benzene formation.

In addition to reducing the damage to the zeolite structure, optimizing the reaction and regeneration of the catalyst is of critical importance in order reduce the migration and sintering of the metal phase. It is widely believed that the dispersion of the metal is the most important factor governing the activity of the MDA catalyst. ${ }^{[60]}$ However, despite decades of intensive investigation, the synthesis of zeolites with highly dispersed metal is exceptionally challenging. Very few examples of catalysts possessing metals with both high dispersion and stability have been reported in the literature for direct non-oxidative methane conversion. Two examples include lattice-confined single-iron sites embedded within a silica $\left(\mathrm{SiO}_{2}\right)$ matrix reported by Guo et al., and nanoceria single-atom platinum catalysts reported by Xie et al. ${ }^{[61]}$ However, these non-zeolite materials operate at extremely high temperatures, above $950{ }^{\circ} \mathrm{C}$. Recently our group reported the synthesis of single-site metal-containing MFI catalysts with superior stability up to $1000^{\circ} \mathrm{C} .^{[20,62]}$ The 


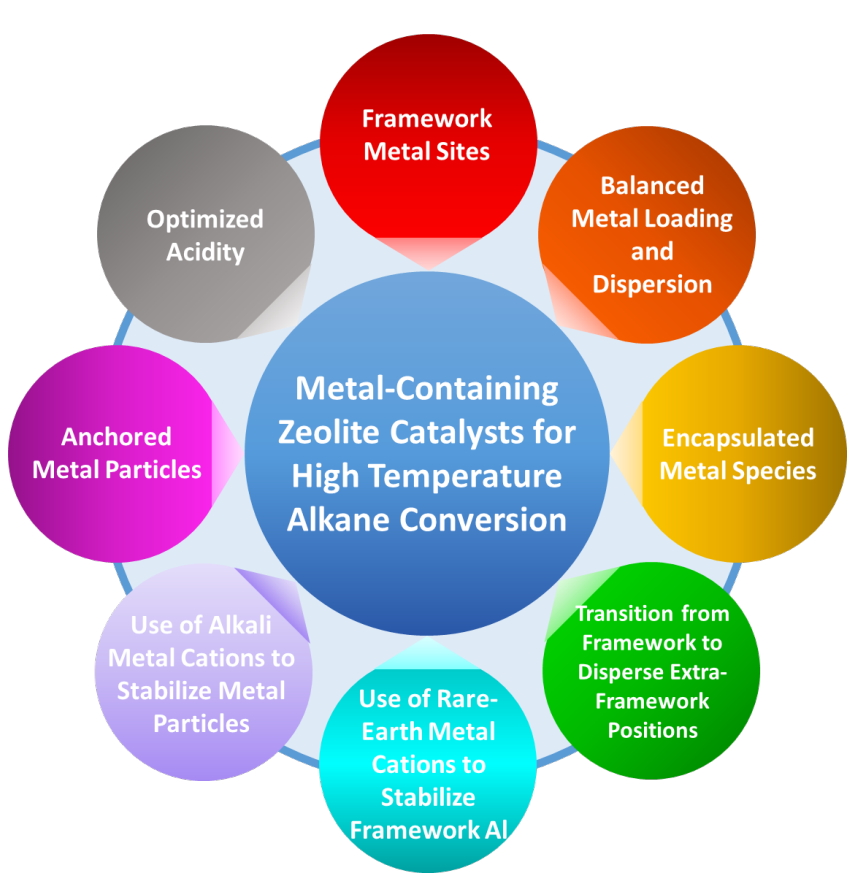

Figure 2. Strategies for improving the performance of metal-containing zeolites catalysts for high temperature alkane conversion.

performance of such a highly stable single-site metal-containing MFI catalyst for MDA was evaluated. ${ }^{\left[{ }^{2 b]}\right]}$ We have shown that the structure of such a single-site metal-containing MFI catalyst remains intact even after exposure to $\mathrm{CH}_{4}$ and air (reductive and oxidative) flow during consecutive reaction and regeneration steps. Steam treatment of the catalyst was also investigated demonstrating that Mo is fully retained within the framework of the nanozeolite catalyst. Furthermore, no silanols were observed after reaction-regeneration cycles or steaming of the catalyst. This further demonstrates that dispersed single-site metals introduced into the MFI zeolite framework stabilized the crystalline structure and prevented the formation of silanol defects.

Thus, despite decades of numerous investigations, the challenge of preparing a suitable MDA catalyst is still unmet. Special attention must be given to the dispersion of the metal phase as single-atom active sites are the most promising for high and stable catalytic performance (Figure 2); they allow for operation under the most favorable conditions (temperatures higher than $700^{\circ} \mathrm{C}$ ) dictated by thermodynamics. In consideration of this goal, new and innovative synthesis procedures will have to be developed, beyond conventional post-synthesis techniques.

\section{Biomass Valorization}

The valorization of biomass (e.g. cellulose, hemicellulose, lignin) to fuels and chemicals covers a large number of different reactions ranging from the conversion of raw feedstocks to the selective transformation of bio-derived molecules. ${ }^{\text {[a] }}$ Many of these reactions involve the use of water as a solvent or co-feed at temperatures above $100{ }^{\circ} \mathrm{C}$. The use of Lewis acid catalysts operating in water is one example that has received increasing attention due to the growing emphasis on the development of sustainable technologies and the use of non-hazardous solvents. ${ }^{[63]}$ It has been reported that materials, such as Sn-Beta, can catalyze a number of different reactions in water using bioderived substrates, ${ }^{[64]}$ and that metals located within the zeolite framework can provide better catalytic sites compared to extraframework metal species. ${ }^{[65]}$ While heterogeneous Lewis acid catalysts (TS-1) have already found commercial success for selective oxidations in aqueous organic solvents, ${ }^{[66]}$ one of the most significant challenges is addressing the stability and recyclability of zeolite catalysts under aggressive conditions such as hot liquid water $(\mathrm{HLW})$. As mentioned earlier, the behavior of metal-containing zeolites operating in hot $\left(\geq 100{ }^{\circ} \mathrm{C}\right)$ aqueous solvents is typically associated with leaching of the metal sites, site restructuring, and amorphization of the zeolite structure. ${ }^{[67]}$ Alternatively, in the absence of an aqueous solvent, the reaction of raw biomass streams (lignin, glycerol) at high temperatures can result in the loss of acid sites and undesirable changes in catalyst activity due to the presence of alkali and alkaline earth metals, ${ }^{[68]}$ as well as the rapid and heavy coking of zeolite catalysts depending on the pore structure and nature of the acid sites of the zeolite. ${ }^{[69]}$

Despite the enormous number of publications concerning biomass reactions catalyzed by both pristine and metalcontaining zeolites the vast majority of these studies are conducted in batch mode, while information about the long-term stability and recyclability of these heterogeneous catalysts is reported much less frequently. ${ }^{[67 b]}$ The fundamental goal is to obtain critical information about the reversible and irreversible deactivation of the catalyst. For this reason catalysts should not be evaluated at $100 \%$ of substrate conversion or at thermodynamic equilibrium as it is often reported. ${ }^{[19]}$ Ideally, experiments where the catalyst operates continuously need to be carried out in order to evaluate the performance and deactivation behavior of the catalyst. In this section a selection of zeolite catalysts containing metals, primarily in framework sites, will be discussed with application in reactions including the isomerization of sugars in HLW, the oxidation of pure glycerol and the dehydration of aqueous glycerol, and the hydrodeoxygenation (HDO) of phenol (Table 2).

\subsection{Isomerization of Sugars}

The heterogeneous catalytic conversion of sugars has received significant attention recently due to the exceptional activity and selectivity of Sn-Beta operating in water, and the potential for the chemo-catalytic valorization of cellulosic biomass to platform chemicals. ${ }^{[70]}$ In addition, zeolite Beta containing group 4 metals (e.g. Ti, Zr) and other Sn-containing zeolites (e.g. MFI) have also been the subject of numerous investigations by several groups ${ }^{[71]}$ however questions concerning the catalyst activity and long term stability in HLW have persisted. ${ }^{[72]}$ The major developments of Sn-containing silica materials for catalytic applications up to 2016/17, including Sn-Beta, have been recently reviewed, ${ }^{[24 b]}$ and zeolite Beta containing group 5 metals (e.g. V, $\mathrm{Nb})$ for glucose conversion in HLW have recently been reported. ${ }^{[73]}$ For clarity, we note that both hydrophobic (low-defect) and hydrophilic (high defect) Sn-Beta can be prepared using either hydrothermal or post-synthetic procedures. ${ }^{[74]}$ However, hydrophobic Sn-Beta is typically reported as prepared by hydrothermal treatment in fluoride media while hydrophilic SnBeta is typically reported as prepared by post-synthetic procedures. 
Following earlier studies performed in batch mode, several groups have investigated the activity of Sn-containing zeolites operating continuously. In 2016, Lari et al. investigated the influence of the framework type (MFI, MOR, FAU, BEA), preparation method (hydrothermally with $\mathrm{OH}^{-}$or $\mathrm{F}^{-}$, alkalineassisted stannation), hydrophobicity, and solvent $\left(\mathrm{H}_{2} \mathrm{O}, \mathrm{MeOH}\right)$ on the activity and stability of $\mathrm{Sn}$ containing zeolites $(0.90-1.87$ $w t \% \mathrm{Sn}$ ) for the isomerization of dihydroxyacetone (DHA) and xylose under industrially relevant conditions, i.e. continuous operation in a fixed-bed reactor over $24 \mathrm{~h} .{ }^{[72]}$ Determination of the turnover frequency (TOF) in batch mode for the conversion of DHA to lactic acid (LA) showed that the Sn-zeolites exhibited similar activity in HLW, while the Sn-BEA and Sn-FAU samples were significantly more active in $\mathrm{MeOH}$. For the conversion of xylose to xylulose in batch mode, hydrothermally prepared SnBEA $\left(\mathrm{F}^{-}\right)$was significantly more active than the other catalysts. For the conversion of DHA to LA in HLW in continuous mode, SnMFI hydrothermally prepared in the presence of $\mathrm{OH}^{-}$was the most stable and selective material, retaining approximately half of its initial activity. Greater loss in long-term stability was observed for the other catalysts. For the conversion of xylose to xylulose in $\mathrm{HLW}$, hydrothermally prepared $\mathrm{Sn}-\mathrm{MFI}\left(\mathrm{OH}^{-}\right)$was the most stable material, losing negligible activity. Hydrothermally prepared SnMFI $\left(\mathrm{F}^{-}\right)$and $\mathrm{Sn}-\mathrm{BEA}\left(\mathrm{F}^{-}\right)$retained $\approx 80 \%$ of their initial activity, followed by Sn-MFI and Sn-MOR prepared by alkaline-assisted stannation (both $\approx 60 \%$ ), and Sn-BEA and Sn-FAU prepared by alkaline-assisted stannation retained the least amount of activity (25 and $8 \%$ ). The greater stability of hydrothermally prepared SnMFI and Sn-BEA was attributed to the higher quality of their Sn sites and greater hydrophobicity. In HLW, the decrease in activity and selectivity was primarily due to amorphization of the zeolite framework and the loss of active Sn sites due to conversion to extra-framework positions and/or leaching. These effects could be mitigated by performing the reaction in $\mathrm{MeOH}$, however, fouling and leaching became significantly pronounced for the MFItype catalysts. Similar work by van de Graaff et al. conducted in batch mode on Sn-containing BEA, MOR, MFI and MWW reported that only the $12 \mathrm{MR}$ zeolites (BEA, MOR) could perform glucose isomerization effectively whereas $10 \mathrm{MR}$ zeolites (MFI, MWW) hardly converted glucose ascribed to the strong confinement of the carbohydrate substrate in the narrower MFI and MWW pores. ${ }^{[75]}$

Continuous flow experiments by Padovan et al. using Sn-Beta prepared by post-synthetic solid-state stannation (10 wt\% Sn) showed a loss of over $90 \%$ of the initial activity for glucose isomerization in $\mathrm{HLW}$ after $30 \mathrm{~h}$ and negligible improvement after reactivation. However, significantly better stability and regenerability was observed when operating in $\mathrm{MeOH} .{ }^{[6]}$ Using $\mathrm{Sn}$-Beta prepared by the same post-synthetic technique, the same group investigated the effect of the $\mathrm{MeOH}: \mathrm{H}_{2} \mathrm{O}$ ratio. The continuous operation of Sn-Beta for $1366 \mathrm{~h}$ ( 57 days) with two regeneration steps was achieved in $\mathrm{MeOH}: \mathrm{H}_{2} \mathrm{O}$ (99:1), with the conversion of fructose maintained at $>70 \%$ and the methyl lactate selectivity at $>60 \%$. Subsequent work by the same group investigated the mechanism of deactivation of Sn-Beta (prepared by post-synthetic solid-state stannation) during continuous-mode glucose isomerization in $\mathrm{MeOH}$ and a solvent mixture of $\mathrm{MeOH}: \mathrm{H}_{2} \mathrm{O}$ of $9: 1$. The presence of water minimizes the accumulation of carbonaceous residues in the pores and reduces the loss of $\mathrm{Sn}-\mathrm{OH}$ and $\mathrm{Si}-\mathrm{OH}$ groups, i.e. minimizing changes to the coordination sphere of active sites. ${ }^{[7]}$ Investigation of the preparation method and $\mathrm{Sn}$ loading for continuous operation in $\mathrm{MeOH}$ has also been investigated. ${ }^{[78]}$

Work by van der Graaff et al. investigated the deactivation mechanism of Sn-Beta operating in continuous mode during the

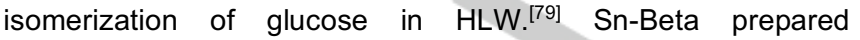
hydrothermally with seeds in HF $(1.79 w t \% \mathrm{Sn})$ suffered the strongest deactivation in the first six hours, losing $\approx 70 \%$ of its initial activity after $24 \mathrm{~h}$, and stabilizing at $\approx 20 \%$ conversion. Regeneration of the catalyst by calcination could partially restore the initial activity, deactivating at a similar rate to the fresh catalyst. Catalyst deactivation was attributed to carbonaceous deposits in the micropores and framework damage evidenced by increased mesoporosity upon repeated use, but no Sn leaching was observed. In comparison, Sn-Beta prepared by post-synthetic stannation (3.80 wt\% Sn) demonstrated lower activity, stabilizing at $\approx 5 \%$ conversion after $24 \mathrm{~h}$. Deactivation of the catalyst was attributed to the loss of micropore volume, framework damage evidenced by the formation of mesopores, and a small amount of Sn leaching. Improved stability of the hydrothermally prepared Sn-Beta could be achieved by operating in a mixture of $\mathrm{EtOH}: \mathrm{H}_{2} \mathrm{O}$ of 9:1 resulting in similar micro- and mesopore values to the fresh catalyst. Additional continuous flow experiments performed in demineralized water and aqueous DHA indicated de-silication took place as well as the loss of micropore volume and formation of mesopores, suggesting framework damage. In addition, the formation of $\mathrm{SnO}_{2}$ particles was also surmised indicating that even if $\mathrm{Sn}$ loss does not appear to occur, site restructuring from framework to extra framework species may happen.

From the above results, consistent with previous batch reaction studies, hydrothermally prepared Sn-containing zeolite catalysts in fluoride media typically exhibit better overall activity and stability compared to post-synthetically prepared catalysts for sugar conversion in HLW. This is attributed primarily to the differences in hydrophobicity and silanol content. The investigation of either hydrophobic or hydrophilic Ti- and Sn-Beta zeolites in batch mode has revealed how the effect of different micropore environments can result in differences in the catalyst activity in HLW. ${ }^{[74,80]}$ In general, hydrophobic Ti- and Sn-Beta zeolites display greater activity (e.g. moles of product generated per mole of metal site, turnover rates, and first-order rate constants) than their hydrophilic counterparts. However, exposure to HLW over time reduces the hydrophobicity of the micropores due to an increase in the number of silanols that act as initiation points for structural amorphization and stabilize extended networks of water molecules. This results in an apparent increase in the free-energy barriers for glucose-fructose isomerization. ${ }^{[81]}$ Furthermore, the choice of framework (e.g. BEA vs MFI) will result in different catalytic activity and stability as a consequence of the pore geometry, active site location, and synthesis procedure. However, while hydrothermally prepared materials are typically more stable, their activity in HLW over time will decrease due to the increasing density of silanols, framework amorphization, loss of framework tetrahedral Sn sites either by leaching or restructuring, and coke formation. ${ }^{[72,79,81 a]}$ A promising strategy to address these issues has involved variation of the solvent as mentioned earlier while other approaches identified have included surface modification using organosilanes. ${ }^{[81 a]}$ 


\section{WILEY-VCH \\ $\mathrm{H}$}

Table 2. Examples of metal-containing zeolites operating outside the "comfort zone" in biomass valorization reactions.

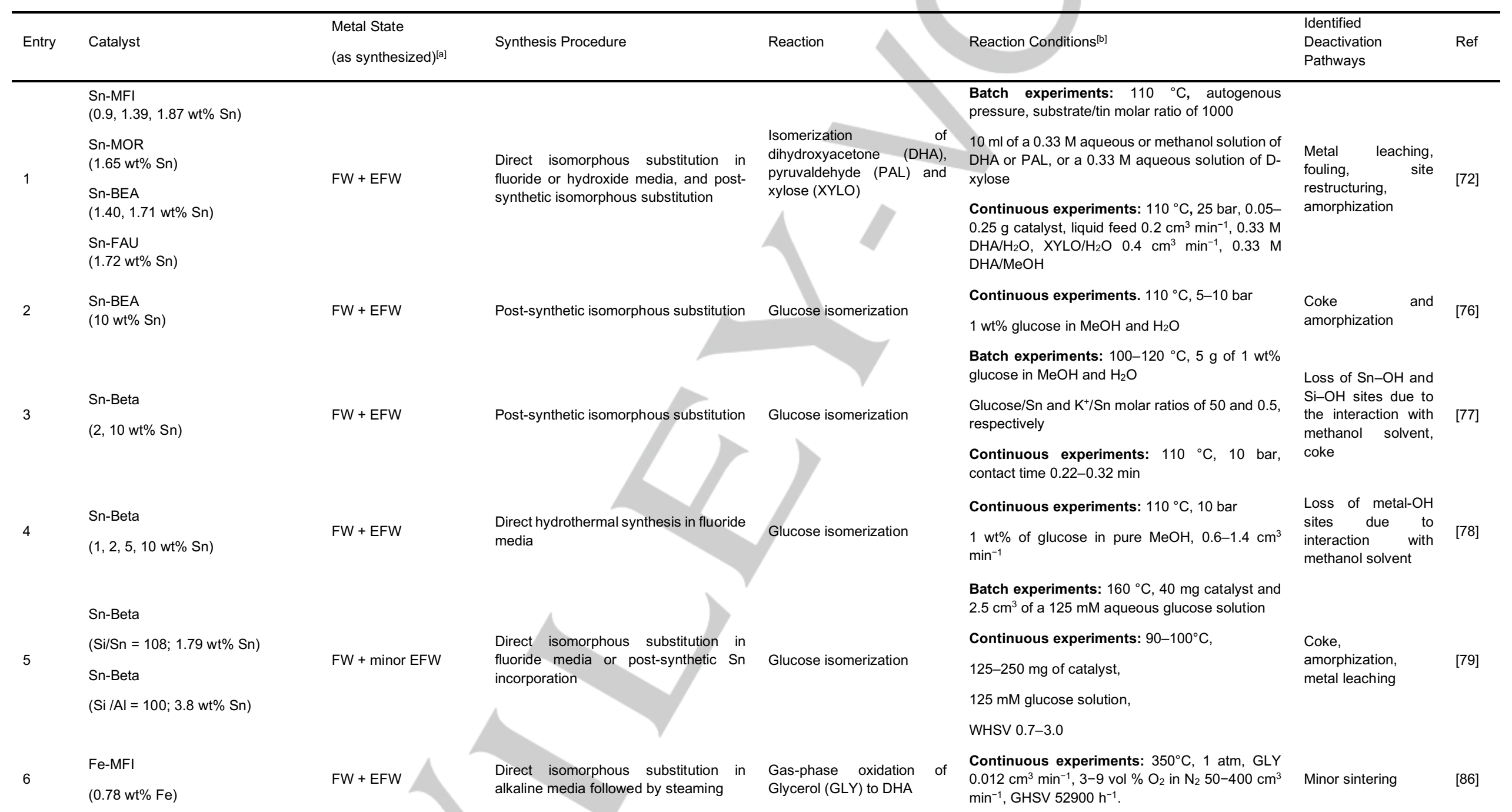




\section{WILEY-VCH}

\section{Fe-MFI}

$(\mathrm{S} / \mathrm{Al}=12,23,60 ; 0.15-2.3 \mathrm{wt} \% \quad \mathrm{FW}+\mathrm{EFW}$

\section{Fe-MFI}

$(\mathrm{Si} / \mathrm{Al}=45,60 ; 0.6 \mathrm{wt} \% \mathrm{Fe})$

$\mathrm{Ni} / \mathrm{HZSM}-5, \mathrm{Ni} / \mathrm{Al}_{2} \mathrm{O}_{3}-\mathrm{HZSM}-5$

$(\mathrm{Si} / \mathrm{Al}=90$ (zeolite); $9.3 \mathrm{wt} \% \mathrm{Ni}, \quad \mathrm{EFW}$

$19.3 \mathrm{wt} \% \mathrm{Al}_{2} \mathrm{O}_{3}$ )

Ni/HZSM-5,

$(10 \mathrm{wt} \% \mathrm{Ni})$

$\mathrm{Ni}-\mathrm{Co} /$ zeolite, Ni/zeolite

$\mathrm{HZSM}-5\left(\mathrm{SiO}_{2} / \mathrm{Al}_{2} \mathrm{O}_{3}=34 ; 10 \mathrm{wt} \%\right.$ $\mathrm{Ni}+10 \mathrm{wt} \% \mathrm{Co}$, or $21 \mathrm{wt} \% \mathrm{Ni})$

$11 \mathrm{HBeta}\left(\mathrm{SiO}_{2} / \mathrm{Al}_{2} \mathrm{O}_{3}=25 ; 10 \mathrm{wt} \% \mathrm{Ni}\right.$ $+10 \mathrm{wt} \% \mathrm{Co})$

$\mathrm{HY}\left(\mathrm{SiO}_{2} / \mathrm{Al}_{2} \mathrm{O}_{3}=12 ; 10 \mathrm{wt} \% \mathrm{Ni}+\right.$ $10 \mathrm{wt} \% \mathrm{Co}$ )

$\mathrm{ZrO}_{2}(10 \mathrm{wt} \% \mathrm{Ni}+10 \mathrm{wt} \% \mathrm{Co})$
Post-synthetic isomorphous substitution Dehydration of GLY Acrolein

Continuous experiments: $320^{\circ} \mathrm{C}, 1 \mathrm{~atm}$, feed $40 \mathrm{wt} \% \mathrm{GLY}$ in $\mathrm{H}_{2} \mathrm{O} 0.1 \mathrm{~cm}^{3} \mathrm{~min}^{-1} \mathrm{~N}_{2}$ or air $15 \mathrm{~cm}^{3}$ $\mathrm{min}^{-1} \mathrm{GHSV} 2770 \mathrm{~h}^{-1}$

Continuous experiments: $320^{\circ} \mathrm{C}, 1 \mathrm{bar}$, GHSV

Direct isomorphous substitution alkaline media and post-synthetic isomorphous substitution

Glycerol oxidehydration acrolein and acrylic acid

\section{$=2770 \mathrm{~h}^{-1}$}

$40 \mathrm{wt} \%$ of glycerol in $\mathrm{H}_{2} \mathrm{O}$,

$0.1 \mathrm{~cm}^{3} \mathrm{~min}^{-1}+15 \mathrm{~cm}^{3} \mathrm{~min}^{-1}$ air

dealumination

Impregnation

experiments: 200 or $250{ }^{\circ} \mathrm{C}, 0.01 \mathrm{~mol}$

Synthesis of colloidal Ni nanoparticles followed by grafting onto support

Phenol hydrodeoxygenation
$\mathrm{Ni} / \mathrm{Al}_{2} \mathrm{O}_{3}-\mathrm{HZSM}-5$,

Phenol hydrodeoxygenation

metal sintering and

leaching

$\mathrm{Ni} / \mathrm{HZSM}-5$ Batch experiments: microreactor cell, $200^{\circ} \mathrm{C}, 30$

$\mathrm{mg}$ of catalyst

particles are however described as stable

Batch experiments: $250{ }^{\circ} \mathrm{C}, 0.5 \mathrm{~g}(5.3 \mathrm{mmol})$ phenol, $10 \mathrm{~g} \mathrm{H}_{2} \mathrm{O}, 0.025 \mathrm{~g}$ catalyst $5 \mathrm{MPa} \mathrm{H}_{2}$

Continuous experiments: $250^{\circ} \mathrm{C}, 60 \mathrm{MPa}$

Phenol hydrodeoxygenation

$0.3,0.4,0.5 \mathrm{~g}$ catalyst, $0.9 \mathrm{~g} / \mathrm{h}$ phenol $(3 \%$ water metal leaching

\section{[a] $\mathrm{FW}=$ Framework metal sites, EFW = Extra-framework metal sites.}

[b] For some publications other catalytic experiments were conducted that fall outside the scope of this review. Here, only relevant reaction conditions are stated. 


\subsection{Oxidation and Dehydration of Glycerol}

The growth in biodiesel production from triglycerides over the last decade has significantly increased the availability of crude glycerol making it a target for valorization into a range of platform chemicals and aromatics. ${ }^{\left[{ }^{82]}\right.}$ Investigation of pristine zeolites for the conversion of aqueous streams of glycerol revealed large pore zeolites performed better than small pore zeolites but severe deactivation occurred due to the leaching of acid sites and the formation of coke. ${ }^{[83]}$ Recent efforts concerning pristine and wetimpregnated metal-containing zeolites have shown that the introduction of mesoporosity, hierarchical or nanosized crystalline structures, modification by alkaline treatment or metal oxides, and the use of tandem catalytic processes can result in significant improvements in the performance of the catalyst. ${ }^{[84]}$ Specifically, isomorphously substituted Fe-MFI zeolites have been investigated for the catalytic conversion of both pure and aqueous streams of glycerol in continuous modes. While it is well known that calcination and steam treatment of Fe-containing zeolites results in the rearrangement of $\mathrm{Fe}$ sites from framework to extra framework positions, ${ }^{[85]}$ the formation of extra framework Fe species has been observed to be beneficial for catalyst stability and activity.

In 2015 Lari et al. investigated the gas phase oxidation of glycerol to DHA at $350{ }^{\circ} \mathrm{C}$ using a series of Al-free and Alcontaining Fe-MFI-type zeolites, prepared hydrothermally or bydry-impregnation, and amorphous materials. ${ }^{[86]}$ In particular, minimizing the acid character and optimization of the redox active Fe sites was targeted in order to better control the selectivity towards DHA due to the temperature of the reaction. Catalyst screening revealed that reducing the concentration of Brønsted acid sites significantly reduces coke formation and the selectivity to dehydration reactions, however, extensive steaming increased the selectivity towards pyruvaldehyde and pyruvic acid due to the formation of large iron oxide particles. The optimized catalyst (hydrothermally prepared Fe-silicalite, $0.78 \mathrm{wt} \% \mathrm{Fe}$, steamed at $600{ }^{\circ} \mathrm{C}$ ) was evaluated over $24 \mathrm{~h}$. Characterization of the sample revealed the presence of both framework and extra framework Fe species, however, redox activity was attributed to the coordinatively unsaturated extra framework $\mathrm{Fe}$ species as framework Fe sites were expected to be fully coordinated. Over $24 \mathrm{~h}$ of time on stream the catalyst demonstrated exceptional stability with the conversion of glycerol remaining unchanged $(\approx$ $70 \%$ ) while the selectivity to DHA slightly decreased suggesting the extra framework $\mathrm{Fe}$ species had undergone a degree of sintering. The optimized Fe-MFI catalyst was further developed by the same group and evaluated as a technical catalyst demonstrating comparable activity to the pure zeolite over $72 \mathrm{~h}$ on stream. ${ }^{[87]}$

In 2018, work by Diallo et al. focused on the dehydration of aqueous glycerol to acrolein at $320{ }^{\circ} \mathrm{C}$ using a series of postsynthetically isomorphously substituted Fe-MFI catalysts $(0.15$ $2.0 \mathrm{wt} \% \mathrm{Fe}$ ) with varying Si/Al ratios of 12,23 and $60 .{ }^{[88]} \mathrm{MFI}$ zeolites with a higher Si/Al ratio afforded Fe-MFI with a lower Fe content and extra framework iron oxide species with greater dispersion. In comparison to pristine $\mathrm{MFI}$, the introduction of $\mathrm{Fe}$ resulted in improved stability, conversion, and selectivity to acrolein over $8 \mathrm{~h}$, with the best performing catalyst possessing the highest Si/Al ratio $(60)$ and a relatively low Fe content $(0.6 \mathrm{wt} \%)$. The catalyst demonstrated stable glycerol conversion and acrolein for up to $24 \mathrm{~h}$ and after a subsequent $25 \mathrm{~h}$ after regeneration. In general, the increase of the Si/Al ratio afforded more stable catalysts, however, no clear relationship between the $\mathrm{Si} / \mathrm{Al}$ ratio and coke content was observed. Interrogation of the coke species by a combination of techniques indicated that the formation of disperse extra framework $\mathrm{Fe}$ species helped to improve the oxidation of coke, reduce the loss of both the external surface area and micropore volume, and resulted in a change in the species of coke formed. This indicates the balance between the Si/Al ratio and Fe content is an important factor for activity as it affects both the spatial distribution of $\mathrm{Fe}$ species in the zeolite and coke formation (Figure 3 ). The dispersion of iron oxide particles is potentially linked to the Si/Al ratio, i.e. a higher Si/Al ratio results in greater dispersion, as it has been shown that the presence of $\mathrm{Al}$ facilitates the extraction of $\mathrm{Fe}$ from the framework. ${ }^{[86,89]}$ Further work by the same group focusing on the synthesis procedure of the catalyst revealed differences in the product selectivity. ${ }^{[90]}$ Hydrothermally prepared Fe-MFI showed a greater selectivity to acrylic acid, attributed to a greater proportion of framework $\mathrm{Fe}^{3+}$ present, compared to the post-synthetically prepared samples, however, it was less stable than the postsynthetically prepared catalysts.

\subsection{Hydrodeoxygenation of Phenol}

The conversion of biomass such as lignin or algae to bio-oil by thermochemical processes such as catalytic fast pyrolysis (CFP) is one of the most promising strategies to utilize biomass for the sustainable production of fuels and chemicals. ${ }^{\left[{ }^{11]}\right.}$ However, due to the significant content of impurities such as water and oxygen, bio-oils obtained from the CFP of biomass such as lignin must be upgraded by hydrodeoxygenation (HDO) before they can be used or blended with conventional petrochemical products. ${ }^{\left[{ }^{92]}\right.}$ Zeolites have been a primary target of research efforts in both CFP and $\mathrm{HDO}$, in particular ZSM-5, due to its selectivity towards gasolinerange alkenes and aromatics. ${ }^{[93]}$ While an enormous number of zeolites catalysts have been tested for optimizing the bio-oils obtained from CFP only a small number of studies have investigated the long-term stability of pristine zeolites, ${ }^{[68 a, 94]}$ and to best of our knowledge, very little information concerning the long-term stability of metal-containing zeolites has been reported. ${ }^{[95]}$ For HDO, a large number of zeolite catalysts have been investigated, ${ }^{[96]}$ including metal-containing zeolites operating in HLW for HDO, ${ }^{[96 b, 97]}$ and in continuous mode for the upgrading of bio-oils (Ni-HZSM-5). ${ }^{\left[{ }^{[8]}\right.}$ In particular, some studies have focused on the stability of the metal phase (prepared by wetimpregnation) for HDO reactions in HLW.

In 2012 Zhao et al. investigated the kinetics of aqueous phenol dehydrogenation between $160-220{ }^{\circ} \mathrm{C}$ under $5 \mathrm{MPa} \mathrm{H}_{2}$ over Ni supported HZSM-5 (Ni/HZSM-5) or Ni supported HZSM5 with $\mathrm{Y}-\mathrm{Al}_{2} \mathrm{O}_{3}\left(\mathrm{Ni} / \mathrm{Al}_{2} \mathrm{O}_{3}-\mathrm{HZSM}-5\right)$ binder in batch mode. ${ }^{[99]}$ The introduction of $\mathrm{y}-\mathrm{Al}_{2} \mathrm{O}_{3}$ as a binder increased the reaction rate of the dehydrogenation of phenol, cyclohexanone and cyclohexene due to the highly dispersed Ni sites, however, dehydrogenation of cyclohexanol was faster over Ni/HZSM-5 due to the higher Brønsted acid site density. Both catalysts were prone to deactivation due to the conversion of Brønsted to Lewis acid sites, and sintering during the reaction and recycling of the catalyst. However, $\mathrm{Ni}$ sintering and leaching was less pronounced for $\mathrm{Ni} / \mathrm{Al}_{2} \mathrm{O}_{3}-\mathrm{HZSM}-5$ compared to Ni/HZSM-5. Stability experiments also revealed that the $\mathrm{Al}_{2} \mathrm{O}_{3}$ binder was susceptible to dissolution 
in HLW, and the presence of carboxylic acids enhanced the leaching of $\mathrm{Ni}$. This is of critical concern as bio-oils contain a significant amount of organic acids. Subsequent work by the same group showed that the treatment of $\mathrm{Ni} / \mathrm{HZSM}-5$ under a reducing atmosphere resulted in the formation of $\mathrm{Ni}^{0}$, prior to immersion in an acetic acid solution maintained under $\mathrm{H}_{2}$, which prevented the leaching of $\mathrm{Ni} .{ }^{[100]}$

In 2016 Huynh et al. investigated the aqueous phase hydrodeoxygeation of phenol over bimetallic $\mathrm{Ni}-\mathrm{Co}$ and monometallic Ni catalysts supported on different zeolites in batch and continuous modes, up to $24 \mathrm{~h}$ on stream at $250{ }^{\circ} \mathrm{C} \cdot{ }^{[101]}$ The best performance was observed using bimetallic $\mathrm{Ni}$-Co over HZSM-5 (Ni-Co/HZSM-5) attributed to its high acid site strength and density, and superior hydrothermal stability, compared to $\mathrm{H}$ Beta and $\mathrm{HY}$ zeolites. Both H-Beta and HY lost a significant degree of their BET surface area after $8 \mathrm{~h}$ on stream. After $24 \mathrm{~h}$ on stream the $\mathrm{Ni}-\mathrm{Co} / \mathrm{HZSM}-5$ catalyst retained $100 \%$ conversion and $90 \%$ selectivity to deoxygenated products, however, no recycling experiments were performed. The presence of Co appeared to have a stabilizing effect, improving the particle dispersion and reducing metal leaching compared to the monometallic Ni/HZSM-5 catalyst. In addition, the Ni-Co/HZSM-5 catalyst produced less coke than the Ni/HZSM- 5 catalyst, and retained a greater degree of its initial BET surface area after $24 \mathrm{~h}$ on stream. While both the Ni/HZSM-5 and Ni-Co/HZSM-5 catalysts lost similar degrees of Brønsted acid sites, the Ni-Co catalyst retained a greater degree of Lewis acid sites.

It is clear that the operation of zeolites in the presence of HLW remains a significant challenge, however, several strategies for improving the performance of metal-containing zeolites offer several paths forward (Figure 3). While significant advances have been made in the understanding of the structure and activity of metal-containing zeolites for certain reactions, e.g. glucose isomerization with $\mathrm{Sn}$-Beta, similar efforts for other biomass

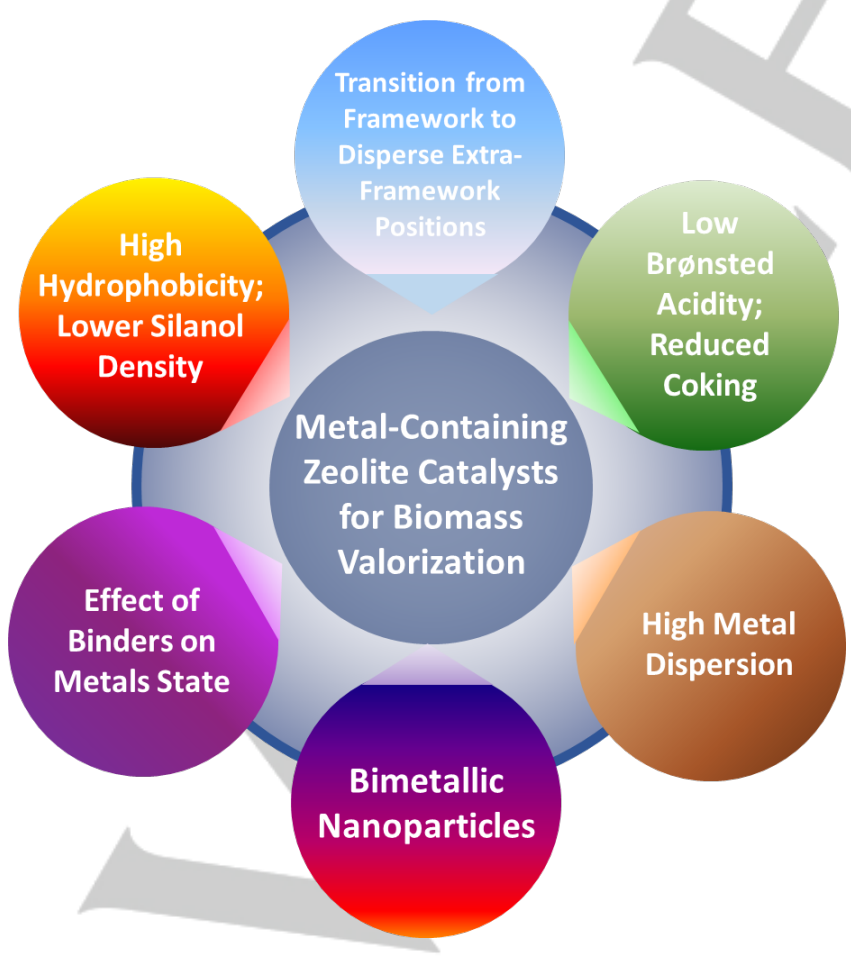

Figure 3. Strategies for improving the performance of metal-containing zeolites catalysts for biomass valorization outside the "comfort zone". valorization reactions are needed. Across different reactions, such as glucose isomerization and glycerol conversion, employing zeolites with a relatively higher $\mathrm{Si}$ content/lower Brønsted acidity and possessing metals located in framework sites has proven to be beneficial for both the catalyst stability (increased hydrophobicity, low coke formation) and performance (high substrate conversion, product selectivity). Low metal loading (0.1-1 wt\%) typically affords superior catalyst performance in terms of TOF and catalyst stability, ${ }^{[78]}$ however, it has been shown that this may require striking a balance between substrate conversion and product selectivity due to a loss in metal dispersion. ${ }^{[86]}$ The development of new strategies for preparing stable metal-containing zeolites for biomass valorization reactions in HLW will revolve around the type of the desired metal active site. It has been shown that the addition of $\mathrm{Y}^{-} \mathrm{Al}_{2} \mathrm{O}_{3}$ binder and the use of different metals affords superior catalyst stability where the metal phase is a nanoparticle,$^{[99,101]}$ however, the preparation and evaluation of framework-containing zeolites with a bimetallic configuration and added binder has yet to be demonstrated.

\section{Conclusions and Outlook}

As the global energy system continues evolving to satisfy both a growing population and a reduction in greenhouse gas emissions, zeolites will continue to play a central role in existing petrochemical and emerging bio-refinery processes. Metalcontaining zeolites offer a surplus of opportunities for developing catalysts with desirable and bifunctional properties due to the numerous combinations of framework structures, zeolite morphologies, Si/Al ratios, active site morphologies, and types of metals.

In this review we have highlighted metal-containing zeolites operating outside the comfort zone for high temperature alkane reactions $\left(\geq 550^{\circ} \mathrm{C}\right)$ and biomass valorization in $\mathrm{HLW}\left(\geq 100^{\circ} \mathrm{C}\right)$, prepared using a variety of strategies and possessing metal sites in various configurations. Specifically, strategies that revolve around the substitution of atoms at T-sites show that metals located at these positions can serve as catalytic sites located in the zeolite framework, as anchoring sites for catalytically active metals, and as precursors to highly disperse extra-framework catalytic sites formed during the post-synthetic treatment or catalytic reaction. This reinforces the importance of scrutinizing the activity and stability behavior of the catalyst as different metals clearly demonstrate different degrees of stability within the zeolite framework whereby the observed activity may represent a combination of behaviors from different sites, potentially exhibiting a synergistic interaction. For example, the preparation of Fe-MFI zeolite catalysts can result in the formation of both framework and extra-framework metal species, however, the former have been implicated as primarily responsible for the observed activity during PDH whereas the latter during the oxidation of glycerol.

As we have noted, determining the stability and recyclability of metal-containing zeolite catalysts under industrially relevant conditions is of critical importance yet infrequently reported. General deactivation pathways and stabilization strategies under different reaction conditions have been identified, but further targeted and in-depth analyses are required. Such studies emphasize how the knowledge and understanding of the catalyst behavior is critical for catalyst development from the laboratory 
scale to mature industrial processes, such as the effect of hydrophobicity on the micropore environment of Sn-Beta for glucose isomerization, and determination of the location of rareearth metals in zeolite $\mathrm{Y}$ for FCC.

Despite over 50 years since zeolites revolutionized the oil refining and petrochemical industries a plethora of opportunities remain for exploring the activity and stability of zeolites for existing and emerging heterogeneous catalytic reactions. Recent developments concerning novel synthesis strategies for $\mathrm{PDH}$ catalysts, such as the use of Sn-Beta to stabilize Pt species, demonstrate that metal-containing zeolites may yet offer a competitive alternative to existing metal-alumina catalysts. As mentioned earlier, for emerging processes such as the CFP and $\mathrm{HDO}$ of biomass, issues concerning the long-term stability and regeneration of metal-containing zeolites remain open and will become increasingly important for the upgrading of pyrolysis oils. Similarly, for processes like the aqueous phase reforming of glycerol and phenol, ${ }^{[102]}$ and the conversion of hemicellulose, ${ }^{[103]}$ the majority of investigations have been performed in batch mode. Strategies such as steaming Al-rich US-Y to generate extraframework Al species that stabilize the zeolite in HLW offer guidance for future work, however, sintering of the metal phase is still an issue. ${ }^{[103 c]}$ Beyond biomass, the application of metalcontaining zeolites for recycling processes represents even greater untapped potential despite the annual global amount of manufactured plastic is comparable to the annual global amount of wood-biomass used to produce bio-energy $(\approx 380 \mathrm{Mt}$ vs 369

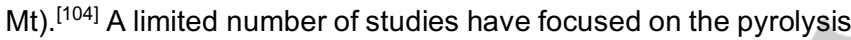
of plastic waste, primarily using pristine zeolites. ${ }^{[105]}$ In combination with the availability and advancements of characterization techniques and computational modelling, the potential of metal-containing zeolites remains as great as ever.

Last but not least, it is important to keep in mind that commercially successful catalysts are:

- Shaped with a binder; these are not always inert and can interact with the zeolite, providing opportunities to further stabilize them. ${ }^{[106]}$

- Loaded in dedicated unit to, for instance, meet the requirements of catalyst regeneration without stopping the commercial production of on-spec products. The chemical industry already provides innovative solutions such as the fluid (FCC for oil cracking) and moving (CCR Platforming for naphtha reforming and $\mathrm{PDH}$ ) beds. It is likely that such solutions could be adapted to meet some of the requirements of the emerging catalysts discussed in this review and shorten the time between invention (laboratory discovery) and innovation (commercial deployment of an invention). ${ }^{[107]}$

\section{Acknowledgements}

Financial support from Industrial Chair ANR-TOTAL "Nanoclean Energy" is acknowledged as well as from the Normandy Region through his RIN Recherche Program. The 111 Project (Grant No. B17020) providing opportunities for future collaboration with Jilin University, China is acknowledged.

Keywords: metal-containing zeolites $\cdot$ catalysis $\cdot$ alkane conversion $\bullet$ biomass $\bullet$ catalyst stability $\bullet$ recyclability
[1] Tracking Clean Energy Progress 2017, International Energy Agency, Paris, France, 2017.

[2] a) Outlook for Energy: A Perspective to 2040, Exxon Mobil Corporation, 2019; b) BP Energy Outlook: 2019 edition, BP p.l.c., 2019

[3] a) W. Vermeiren, J.-P. Gilson, Top. Catal. 2009, 52, 1131$1161 ;$ b) A. F. Masters, T. Maschmeyer, Microporous Mesoporous Mater. 2011, 142, 423-438.

[4] A. W. Petrov, D. Ferri, F. Krumeich, M. Nachtegaal, J. A van Bokhoven, O. Kröcher, Nat. Commun. 2018, 9, 1-8.

[5] I. Sádaba, M. L. Granados, A. Riisager, E. Taarning, Green Chem. 2015, 17, 4133-4145.

[6] N. Kosinov, F. J. Coumans, G. Li, E. Uslamin, B. Mezari, A. S. Wijpkema, E. A. Pidko, E. J. Hensen, J. Catal. 2017, 346, 125-133.

[7] a) T. Ennaert, J. Van Aelst, J. Dijkmans, R. De Clercq, W. Schutyser, M. Dusselier, D. Verboekend, B. F. Sels, Chem. Soc. Rev. 2016, 45, 584-611; b) A. R. Maag, G. A. Tompsett, J. Tam, C. A. Ang, G. Azimi, A. D. Carl, X. Huang, L. J. Smith, R. L. Grimm, J. Q. Bond, PCCP 2019, 21, 17880-17892.

[8] a) C. H. Tempelman, E. J. Hensen, Appl. Catal. B 2015 176, 731-739; b) J. Jae, G. A. Tompsett, A. J. Foster, K. D. Hammond, S. M. Auerbach, R. F. Lobo, G. W. Huber, J. Catal. 2011, 279, 257-268.

[9] T. W. Hansen, A. T. DeLaRiva, S. R. Challa, A. K. Datye, Acc. Chem. Res. 2013, 46, 1720-1730.

[10] A. Galadima, O. Muraza, Microporous Mesoporous Mater. 2017, 249, 42-54.

[11] a) T. Blasco, M. A. Camblor, A. Corma, P. Esteve, A. Martínez, C. Prieto, S. Valencia, Chem. Commun. 1996 2367-2368; b) M. A. Camblor, A. Corma, S. Valencia, J. Mater. Chem. 1998, 8, 2137-2145.

[12] a) P. A. Zapata, J. Faria, M. P. Ruiz, R. E. Jentoft, D. E. Resasco, J. Am. Chem. Soc. 2012, 134, 8570-8578; b) P. A. Zapata, Y. Huang, M. A. Gonzalez-Borja, D. E. Resasco, J. Catal. 2013, 308, 82-97.

[13] G. Caeiro, P. Magnoux, J. Lopes, F. R. Ribeiro, S. Menezes, A. Costa, H. Cerqueira, Appl. Catal. A 2006, 314, 160-171.

[14] J. N. Louwen, S. Simko, K. Stanciakova, R. E. Bulo, B. M. Weckhuysen, E. T. Vogt, J. Phys. Chem. C 2020, 124, 4626-4636.

[15] a) H. E. van der Bij, B. M. Weckhuysen, Chem. Soc. Rev. 2015, 44, 7406-7428; b) U. Khalil, O. Muraza, H. Kondoh, G. Watanabe, Y. Nakasaka, A. Al-Amer, T. Masuda, Energy Fuels 2016, 30, 1304-1309.

[16] a) E. Vogt, B. Weckhuysen, Chem. Soc. Rev. 2015, 44, 7342-7370; b) P. Tian, Y. Wei, M. Ye, Z. Liu, ACS Catal. 2015, 5, 1922-1938.

[17] a) J. A. Melero, J. Iglesias, A. Garcia, Energy Environ. Sci. 2012, 5, 7393-7420; b) M. J. Climent, A. Corma, S. Iborra, Green Chem. 2014, 16, 516-547.

[18] L. Nemeth, S. R. Bare, in Adv. Catal., Vol. 57, Elsevier, 2014, pp. 1-97.

[19] H. Y. Luo, J. D. Lewis, Y. Román-Leshkov, Annu. Rev. Chem. Biomol. Eng 2016, 7, 663-692.

[20] J. Grand, S. N. Talapaneni, A. Vicente, C. Fernandez, E. Dib, H. A. Aleksandrov, G. N. Vayssilov, R. Retoux, P. Boullay, J.-P. V. Gilson, Valentin, S. Mintova, Nat. Mater. 2017, 16, 1010-1015.

[21] S. Narayanan, A. Sultana, Appl. Catal. A 1998, 167, 103111.

[22] N. Salman, C. Rüscher, J.-C. Buhl, W. Lutz, H. Toufar, M. Stöcker, Microporous Mesoporous Mater. 2006, 90, 339346.

[23] C. J. Heard, L. Grajciar, C. M. Rice, S. M. Pugh, P. Nachtigall, S. E. Ashbrook, R. E. Morris, Nat. Commun. 2019, 10, 1-7.

[24] a) C. Hammond, in Stud. Surf. Sci. Catal., Vol. 177, Elsevier, 2017, pp. 567-611; b) P. Ferrini, J. Dijkmans, R. 
De Clercq, S. Van de Vyver, M. Dusselier, P. A. Jacobs, B. F. Sels, Coord. Chem. Rev. 2017, 343, 220-255.

[25] a) C. Hammond, D. Padovan, G. Tarantino, R. Soc. Open Sci. 2018, 5, 171315; b) N. Kosinov, C. Liu, E. J. Hensen, E. A. Pidko, Chem. Mater. 2018, 30, 3177-3198; c) J. P. Pariente, M. Sánchez-Sánchez, Structure and Reactivity of Metals in Zeolite Materials, Springer, Cham, 2018.

[26] a) N. Kosinov, E. J. Hensen, Adv. Mater. 2020, 2002565

b) P. Sudarsanam, E. Peeters, E. V. Makshina, V. I. Parvulescu, B. F. Sels, Chem. Soc. Rev. 2019, 48, 23662421.

[27] a) J. J. Sattler, J. Ruiz-Martinez, E. Santillan-Jimenez, B. M. Weckhuysen, Chem. Rev. 2014, 114, 10613-10653; b) R. Cortright, J. Dumesic, J. Catal. 1994, 148, 771-778; c) R. Cortright, J. Dumesic, J. Catal. 1995, 157, 576-583; d) E. Rombi, M. G. Cutrufello, V. Solinas, S. De Rossi, G. Ferraris, A. Pistone, Appl. Catal. A 2003, 251, 255-266.

[28] R. L. Puurunen, B. M. Weckhuysen, J. Catal. 2002, 210, 418-430.

[29] L. Wachowski, P. Kirszensztejn, R. Łopatka, B. Czajka, Mater. Chem. Phys. 1994, 37, 29-38.

[30] M. Shamzhy, M. Opanasenko, P. Concepción, A Martínez, Chem. Soc. Rev. 2019, 48, 1095-1149.

[31] a) J. M. Hill, R. Cortright, J. Dumesic, Appl. Catal. A 1998, 168, 9-21; b) R. D. Cortright, J. M. Hill, J. A. Dumesic, Catal. Today 2000, 55, 213-223.

[32] a) L. Liu, U. Diaz, R. Arenal, G. Agostini, P. Concepción, A. Corma, Nat. Mater. 2017, 16, 132-138; b) L. Liu, M. Lopez-Haro, C. W. Lopes, C. Li, P. Concepcion, L. Simonelli, J. J. Calvino, A. Corma, Nat. Mater. 2019, 18, 866-873.

[33] a) Y. Wang, Z.-P. Hu, W. Tian, L. Gao, Z. Wang, Z.-Y. Yuan, Catal. Sci. Technol. 2019, 9, 6993-7002; b) Z. Xu Y. Yue, X. Bao, Z. Xie, H. Zhu, ACS Catal. 2019, 10, 818828.

[34] R. Baran, T. Onfroy, S. Casale, S. Dzwigaj, J. Phys. Chem. C 2014, 118, 20445-20451.

[35] C. Chen, S. Zhang, Z. Wang, Z.-Y. Yuan, J. Catal. 2020, 383, 77-87.

[36] C. Chen, M. Sun, Z. Hu, Y. Liu, S. Zhang, Z.-Y. Yuan, Chin. J. Catal. 2020, 41, 276-285.

[37] a) K. Chalupka, C. Thomas, Y. Millot, F. Averseng, S. Dzwigaj, J. Catal. 2013, 305, 46-55; b) M. Trejda, Y. Millot, K. Chalupka, S. Dzwigaj, Appl. Catal. A 2019, 579, 1-8.

[38] J. H. Yun, R. F. Lobo, J. Catal. 2014, 312, 263-270.

[39] J. R. Mowry, R. F. Anderson, J. A. Johnson, Oil Gas J. 1985, 83, 128-131.

[40] a) P. Meriaudeau, G. Sapaly, C. Naccache, J. Mol. Catal. 1993, 81, 293-300; b) S.-W. Choi, W.-G. Kim, J.-S. So, J. S. Moore, Y. Liu, R. S. Dixit, J. G. Pendergast, C. Sievers, D. S. Sholl, S. Nair, J. Catal. 2017, 345, 113-123.

[41] M. Nakai, K. Miyake, R. Inoue, K. Ono, H. Al Jabri, Y. Hirota, Y. Uchida, S. Tanaka, M. Miyamoto, Y. Oumi, Catal. Sci. Technol. 2019, 9, 6234-6239.

[42] a) H. Cerqueira, G. Caeiro, L. Costa, F. R. Ribeiro, J. Mol. Catal. A: Chem. 2008, 292, 1-13; b) M. Al-Sabawi, J. Chen, S. Ng, Energy Fuels 2012, 26, 5355-5372; c) P. Bai, U. J. Etim, Z. Yan, S. Mintova, Z. Zhang, Z. Zhong, X. Gao, Cat. Rev. - Sci. Eng. 2019, 61, 333-405.

[43] A. Akah, M. Al-Ghrami, M. Saeed, M. A. B. Siddiqui, Int. J. Ind. Chem. 2017, 8, 221-233.

[44] a) R. Pompea, S. Järóasb, N.-G. Vannerbergb, Appl. Catal. 1984, 13, 171-179; b) F. Mauge, J. Courcelle, P Engelhard, P. Gallezot, J. Grosmangin, in Stud. Surf. Sci. Catal., Vol. 28, Elsevier, 1986, pp. 803-809.

[45] E. Sousa-Aguiar, in Zeolites and Zeolite-Like Materials (Eds.: B. Sels, K. LM), Elsevier, Amsterdam, 2016, pp. 265-282.

[46] a) G. de la Puente, E. F. Souza-Aguiar, F. M. a. Z. Zotin, V. L. D. Camorim, U. Sedran, Appl. Catal. A 2000, 197, 41-46; b) F. Schüßler, S. Schallmoser, H. Shi, G. L. Haller, E. Ember, J. A. Lercher, ACS Catal. 2014, 4, 1743-1752. a) J. Scherzer, J. L. Bass, F. D. Hunter, J. Phys. Chem. 1975, 79, 1194-1199; b) J. Scherzer, J. Bass, J. Catal.

[48] J. 143-147. Jan Bokhoven, A. Roest, D. Koningsberger, J. Miller, G. Nachtegaal, A. Kentgens, J. Phys. Chem. B 2000, 104, 6743-6754.

[49] a) N.-N. Wang, Y. Wang, H.-F. Cheng, Z. Tao, J. Wang, W.-Z. Wu, RSC Adv. 2013, 3, 20237-20245; b) Y. Shanqing, T. Huiping, D. Zhenyu, L. Jun, Chin. J. Catal. 2010, 31, 1263-1270.

[50] F. Schüßler, E. A. Pidko, R. Kolvenbach, C. Sievers, E. J. Hensen, R. A. van Santen, J. A. Lercher, J. Phys. Chem. C 2011, 115, 21763-21776.

[51] L. Zhang, Y. Qin, X. Zhang, X. Gao, L. Song, Ind. Eng. Chem. Res. 2019, 58, 14016-14025.

[52] a) A. Corma, E. Corresa, Y. Mathieu, L. Sauvanaud, S. AlBogami, M. Al-Ghrami, A. Bourane, Catal. Sci. Technol. 2017, 7, 12-46; b) W. Nabgan, M. Rashidzadeh, B. Nabgan, Environ. Chem. Lett. 2018, 16, 507-522.

[53] P. Schwach, X. Pan, X. Bao, Chem. Rev. 2017, 117, 8497-8520.

[54] M. T. Portilla, F. J. Llopis, C. Martínez, Catal. Sci. Technol. 2015, 5, 3806-3821.

[55] C. Sun, G. Fang, X. Guo, Y. Hu, S. Ma, T. Yang, J. Han H. Ma, D. Tan, X. Bao, J. Energy Chem. 2015, 24, 257263.

[56] Y.-H. Kim, R. W. Borry III, E. Iglesia, Microporous Mesoporous Mater. 2000, 35, 495-509.

[57] a) J. Gao, Y. Zheng, J.-M. Jehng, Y. Tang, I. E. Wachs, S. G. Podkolzin, Science 2015, 348, 686-690; b) R. W. Borry, Y. H. Kim, A. Huffsmith, J. A. Reimer, E. Iglesia, J. Phys. Chem. B 1999, 103, 5787-5796.

[58] B. Liu, J. Leung, L. Li, C. Au, A.-C. Cheung, Chem. Phys. Lett. 2006, 430, 210-214.

[59] a) H. Ma, R. Kojima, R. Ohnishi, M. Ichikawa, Appl. Catal. A 2004, 275, 183-187; b) S. J. Han, S. K. Kim, A. Hwang, S. Kim, D.-Y. Hong, G. Kwak, K.-W. Jun, Y. T. Kim, Appl. Catal. B 2019, 241, 305-318; c) R. Borry, E. C. Lu, Y.-H. Kim, E. Iglesia, Stud. Surf. Sci. Catal 1998, 119, 403-410; d) Z. Ismagilov, L. Tsikoza, E. Matus, G. Litvak, I. Ismagulova, O. Sukhova, Eurasian Chem. Technol. J. 2005, 7, 115-121.

[60] I. Vollmer, A. Mondal, I. Yarulina, E. Abou-Hamad, F Kapteijn, J. Gascon, Appl. Catal. A 2019, 574, 144-150.

[61] a) X. Guo, G. Fang, G. Li, H. Ma, H. Fan, L. Yu, C. Ma, X. Wu, D. Deng, M. Wei, Science 2014, 344, 616-619; b) P. Xie, T. Pu, A. Nie, S. Hwang, S. C. Purdy, W. Yu, D. Su, J. T. Miller, C. Wang, ACS Catal. 2018, 8, 4044-4048. a) F. Dubray, S. Moldovan, C. Kouvatas, J. Grand, C. Aquino, N. Barrier, J.-P. Gilson, N. Nesterenko, D. Minoux, S. Mintova, J. Am. Chem. Soc. 2019, 141, 8689-8693; b) S. K. Konnov, F. Dubray, E. B. Clatworthy, C. Kouvatas, J.-P. Gilson, J.-P. Dath, D. Minoux, C. Aquino, V. Valtchev, S. Moldovan, S. Koneti, N. Nesterenko, S. Mintova, Angew. Chem. Int. Ed. 2020, 10.1002/anie.202006524.

[63] a) P. T. Anastas, J. C. Warner, Green Chemistry: Theory and Practice, Oxford University Press, New York, 1998; b) M. Moliner, Dalton Trans. 2014, 43, 4197-4208; c) P. Y. Dapsens, C. Mondelli, J. Pérez-Ramírez, Chem. Soc. Rev. 2015, 44, 7025-7043; d) G. Li, B. Wang, D. E. Resasco, ACS Catal. 2019, 10, 1294-1309.

[64] M. Koehle, R. F. Lobo, Catal. Sci. Technol. 2016, 6, 30183026.

[65] S. Roy, K. Bakhmutsky, E. Mahmoud, R. F. Lobo, R. J. Gorte, ACS Catal. 2013, 3, 573-580.

[66] M. G. Clerici, in Metal Oxide Catalysis (Eds.: S. D. Jackson, J. S. J. Hargreaves), Wiley-VCH Weinheim, 2008, pp. 705-754.

[67] a) J. P. Lange, Angew. Chem. Int. Ed. 2015, 54, 1318613197; b) C. Hammond, Green Chem. 2017, 19, 27112728.

[68] a) V. Paasikallio, C. Lindfors, E. Kuoppala, Y. Solantausta, A. Oasmaa, J. Lehto, J. Lehtonen, Green Chem. 2014, 16, 3549-3559; b) K. Wang, J. Zhang, B. H. Shanks, R. C. Brown, Appl. Energy 2015, 148, 115-120; c) G. Yildiz, F. 
Ronsse, R. Venderbosch, R. van Duren, S. R. Kersten, W. Prins, Appl. Catal. B 2015, 168, 203-211; d) S. D. Stefanidis, E. Heracleous, D. T. Patiaka, K. G. Kalogiannis, C. M. Michailof, A. A. Lappas, Biomass Bioenerg. 2015, 83, 105-115.

[69] a) Z. Ma, E. Troussard, J. A. van Bokhoven, Appl. Catal. A 2012, 423, 130-136; b) Z. Ma, J. A. van Bokhoven, ChemCatChem 2012, 4, 2036-2044; c) D. Sun, Y Yamada, S. Sato, W. Ueda, Green Chem. 2017, 19, 31863213.

[70] I. Delidovich, R. Palkovits, ChemSusChem 2016, 9, 547561.

[71] a) A. Corma, L. T. Nemeth, M. Renz, S. Valencia, Nature 2001, 412, 423-425; b) A. Corma, M. E. Domine, L. Nemeth, S. Valencia, J. Am. Chem. Soc. 2002, 124, 31943195; c) E. Taarning, S. Saravanamurugan, M. Spangsberg Holm, J. Xiong, R. M. West, C. H. Christensen, ChemSusChem 2009, 2, 625-627; d) M. Moliner, Y. Román-Leshkov, M. E. Davis, Proc. Natl. Acad. Sci. U.S.A. 2010, 107, 6164-6168.

[72] G. M. Lari, P. Y. Dapsens, D. Scholz, S. Mitchell, C. Mondelli, J. Pérez-Ramírez, Green Chem. 2016, 18, 1249 1260.

[73] a) J. Sebastian, M. Zheng, X. Li, J. Pang, C. Wang, T. Zhang, J. Energy Chem. 2019, 34, 88-95; b) N. Candu, M. El Fergani, M. Verziu, B. Cojocaru, B. Jurca, N. Apostol, C. Teodorescu, V. I. Parvulescu, S. M. Coman, Catal. Today 2019, 325, 109-116.

[74] P. Wolf, M. Valla, F. Nunez-Zarur, A. Comas-Vives, A. J Rossini, C. Firth, H. Kallas, A. Lesage, L. Emsley, C. Coperet, ACS Catal. 2016, 6, 4047-4063.

[75] W. N. van der Graaff, C. H. Tempelman, E. A. Pidko, E. J. Hensen, Catal. Sci. Technol. 2017, 7, 3151-3162.

[76] D. Padovan, C. Parsons, M. S. Grasina, C. Hammond Green Chem. 2016, 18, 5041-5049.

[77] D. Padovan, L. Botti, C. Hammond, ACS Catal. 2018, 8 , 7131-7140.

[78] L. Botti, R. Navar, S. Tolborg, J. S. Martinez-Espin, D. Padovan, E. Taarning, C. Hammond, Top. Catal. 2019 62, 1178-1191.

[79] W. N. van der Graaff, C. H. Tempelman, F. C. Hendriks, J. Ruiz-Martinez, S. Bals, B. M. Weckhuysen, E. A. Pidko, E. J. Hensen, Appl. Catal. A 2018, 564, 113-122.

[80] a) R. Gounder, M. E. Davis, AlChE J. 2013, 59, 33493358; b) R. Gounder, M. E. Davis, J. Catal. 2013, 308, 176-188.

[81] a) M. J. Cordon, J. N. Hall, J. W. Harris, J. S. Bates, S.-J. Hwang, R. Gounder, Catal. Sci. Technol. 2019, 9, 16541668; b) M. J. Cordon, J. W. Harris, J. C. Vega-Vila, J. S. Bates, S. Kaur, M. Gupta, M. E. Witzke, E. C. Wegener, J. T. Miller, D. W. Flaherty, J. Am. Chem. Soc. 2018, 140, 14244-14266

[82] a) G. Dodekatos, S. Schünemann, H. Tüysüz, ACS Catal. 2018, 8, 6301-6333; b) F. Wang, W. Xiao, L. Gao, G. Xiao, RSC Adv. 2016, 6, 42984-42993.

[83] A. S. de Oliveira, S. J. Vasconcelos, J. R. de Sousa, F. F. de Sousa, M. Josué Filho, A. C. Oliveira, Chem. Eng. J. 2011, 168, 765-774.

[84] a) H. Zhang, Z. Hu, L. Huang, H. Zhang, K. Song, L. Wang, Z. Shi, J. Ma, Y. Zhuang, W. Shen, ACS Catal. 2015, 5, 2548-2558; b) R. Beerthuis, L. Huang, N. R. Shiju, G. Rothenberg, W. Shen, H. Xu, ChemCatChem 2018, 10, 211-221; c) B. A. Qureshi, X. Lan, M. T. Arslan, T. Wang, Ind. Eng. Chem. Res. 2019, 58, 12611-12622; d) C. D. Lago, H. P. Decolatti, L. G. Tonutti, B. O. Dalla Costa, C. A. Querini, J. Catal. 2018, 366, 16-27; e) Z.-Y. Huang, C.-H. Xu, J. Meng, C.-F. Zheng, H.-W. Xiao, J. Chen, Y.-X. Zhang, J. Environ. Chem. Eng. 2014, 2, 598604; f) Z. Wu, K. Zhao, S. Ge, Z. Qiao, J. Gao, T. Dou, A. C. Yip, M. Zhang, ACS Sustainable Chem. Eng. 2016, 4, 4192-4207.

[85] a) A. Ribera, I. Arends, S. De Vries, J. Pérez-Ramırez, R. Sheldon, J. Catal. 2000, 195, 287-297; b) J. PérezRamírez, G. Mul, F. Kapteijn, J. Moulijn, A. Overweg, A. Doménech, A. Ribera, I. Arends, J. Catal. 2002, 207, 113-
126; c) J. Pérez-Ramírez, J. Groen, A. Brückner, M. S. Kumar, U. Bentrup, M. Debbagh, L. Villaescusa, J. Catal. 2005, 232, 318-334.

[86] G. M. Lari, C. Mondelli, J. Pérez-Ramírez, ACS Catal. 2015, 5, 1453-1461.

[87] G. M. Lari, C. Mondelli, S. Papadokonstantakis, M. Morales, K. Hungerbühler, J. Pérez-Ramírez, React. Chem. Eng. 2016, 1, 106-118.

[88] M. M. Diallo, S. Laforge, Y. Pouilloux, J. Mijoin, Catal. Lett. 2018, 148, 2283-2303.

[89] J. Pérez-Ramírez, J. Catal. 2004, 227, 512-522.

[90] M. M. Diallo, S. Laforge, Y. Pouilloux, J. Mijoin, Catal. Commun. 2019, 126, 21-25.

[91] G. Yildiz, F. Ronsse, R. Van Duren, W. Prins, Renew. Sust. Energ. Rev. 2016, 57, 1596-1610.

[92] W. Jin, L. Pastor - Pérez, D. Shen, A. Sepúlveda Escribano, S. Gu, T. Ramirez Reina, ChemCatChem 2019, 11, 924-960.

[93] a) M. B. Griffin, K. lisa, H. Wang, A. Dutta, K. A. Orton, R. J. French, D. M. Santosa, N. Wilson, E. Christensen, C. Nash, Energy Environ. Sci. 2018, 11, 2904-2918; b) R. Liu, M. M. Rahman, M. Sarker, M. Chai, C. Li, J. Cai, Fuel Process. Technol. 2020, 199, 106301; c) C. Lok, J. Van Doorn, G. A. Almansa, Renew. Sust. Energ. Rev. 2019, 113, 109248.

[94] a) T. R. Carlson, Y.-T. Cheng, J. Jae, G. W. Huber Energy Environ. Sci. 2011, 4, 145-161; b) J. Jae, R. Coolman, T. Mountziaris, G. W. Huber, Chem. Eng. Sci. 2014, 108, 33-46; c) G. r. Yildiz, T. Lathouwers, H. E. Toraman, K. M. Van Geem, G. B. Marin, F. Ronsse, R. Van Duren, S. R. Kersten, W. Prins, Energy Fuels 2014, 28, 4560-4572; d) S. Shao, H. Zhang, R. Xiao, X. Li, Y. Cai, Energy Convers. Manage. 2018, 155, 175-181; e) K. G. Kalogiannis, S. D. Stefanidis, A. A. Lappas, Fuel Process. Technol. 2019, 186, 99-109.

[95] a) Y. T. Cheng, J. Jae, J. Shi, W. Fan, G. W. Huber, Angew. Chem. Int. Ed. 2012, 51, 1387-1390; b) P. S Rezaei, H. Shafaghat, W. M. A. W. Daud, Green Chem. 2016, 18, 1684-1693.

[96] a) Y. Shi, E. Xing, K. Wu, J. Wang, M. Yang, Y. Wu, Catal. Sci. Technol. 2017, 7, 2385-2415; b) W. Luo, W. Cao, P. C. Bruijnincx, L. Lin, A. Wang, T. Zhang, Green Chem. 2019, 21, 3744-3768.

[97] J. Zhang, J. Sun, Y. Wang, Green Chem. 2020, 22, 10721098.

a) A. G. Gayubo, B. Valle, A. T. Aguayo, M. Olazar, J. Bilbao, Energy Fuels 2009, 23, 4129-4136; b) A. Gayubo, B. Valle, A. Aguayo, M. Olazar, J. Bilbao, J. Chem. Technol. Biotechnol. 2010, 85, 132-144; c) B. Valle, A. G. Gayubo, A. Alonso, A. T. Aguayo, J. Bilbao, Appl. Catal. B 2010, 100, 318-327; d) B. Valle, A. G. Gayubo, A. T. Aguayo, M. Olazar, J. Bilbao, Energy Fuels 2010, 24, 2060-2070; e) B. Valle, P. Castaño, M. Olazar, J. Bilbao, A. G. Gayubo, J. Catal. 2012, 285, 304-314.

[99] C. Zhao, S. Kasakov, J. He, J. A. Lercher, J. Catal. 2012, 296, 12-23.

[100] Z. A. Chase, S. Kasakov, H. Shi, A. Vjunov, J. L. Fulton, D. M. Camaioni, M. Balasubramanian, C. Zhao, Y. Wang, J. A. Lercher, Chem. Eur. J. 2015, 21, 16541-16546.

[101] T. M. Huynh, U. Armbruster, C. R. Kreyenschulte, L. H. Nguyen, B. M. Phan, D. A. Nguyen, A. Martin, Catalysts 2016, 6, 176.

[102] a) K. Murata, I. Takahara, M. Inaba, React. Kinet. Catal. Lett. 2008, 93, 59-66; b) G. Wen, Y. Xu, H. Ma, Z. Xu, Z. Tian, Int. J. Hydrogen Energy 2008, 33, 6657-6666; c) P. Gogoi, A. S. Nagpure, P. Kandasamy, C. Satyanarayana, T. Raja, Sustainable Energy Fuels 2020; d) B. Yan, W. Li, J. Tao, N. Xu, X. Li, G. Chen, Int. J. Hydrogen Energy 2017, 42, 6674-6682; e) X. Li, B. Yan, J. Zhang, N. Xu, J. Tao, R. Zhang, B. Liu, Z. Sun, G. Chen, Int. J. Hydrogen Energy 2018, 43, 649-658.

[103] a) L. Faba, B. T. Kusema, E. V. Murzina, A. Tokarev, N. Kumar, A. Smeds, E. Díaz, S. Ordóñez, P. Mäki-Arvela, S. Willför, Microporous Mesoporous Mater. 2014, 189, 189199; b) D. Y. Murzin, B. Kusema, E. V. Murzina, A. Aho, A. 
Tokarev, A. S. Boymirzaev, J. Wärnå, P. Y. Dapsens, C. Mondelli, J. Pérez-Ramírez, J. Catal. 2015, 330, 93-105;

c) T. Ennaert, J. Geboers, E. Gobechiya, C. M. Courtin, M. Kurttepeli, K. Houthoofd, C. E. Kirschhock, P. C. Magusin, S. Bals, P. A. Jacobs, ACS Catal. 2015, 5, 754-768; d) T. Ennaert, S. Feys, D. Hendrikx, P. A. Jacobs, B. F. Sels, Green Chem. 2016, 18, 5295-5304.

[104] a) R. Geyer, J. R. Jambeck, K. L. Law, Sci. Adv. 2017, 3, e1700782; b) N. Tripathi, C. D. Hills, R. S. Singh, C. J. Atkinson, npj Clim. Atmos. Sci. 2019, 2, 1-10.

[105] a) R. Miandad, M. Barakat, A. S. Aburiazaiza, M. Rehan, A. Nizami, Process Saf. Environ. Prot. 2016, 102, $822-$ 838; b) S. D. A. Sharuddin, F. Abnisa, W. M. A. W. Daud M. K. Aroua, Energy Convers. Manage. 2016, 115, 308326; c) S. Al-Salem, A. Antelava, A. Constantinou, G. Manos, A. Dutta, J. Environ. Manage. 2017, 197, 177-198.

[106] L. Lakiss, J.-P. Gilson, V. Valtchev, S. Mintova, A. Vicente, A. Vimont, R. Bedard, S. Abdo, J. Bricker, Microporous Mesoporous Mater. 2020, 299, 110114.

[107] a) J. A. Moulijn, A. Van Diepen, F. Kapteijn, Appl. Catal. A 2001, 212, 3-16; b) S. Sie, Appl. Catal. A 2001, 212, 129151. 


\section{Entry for the Table of Contents}
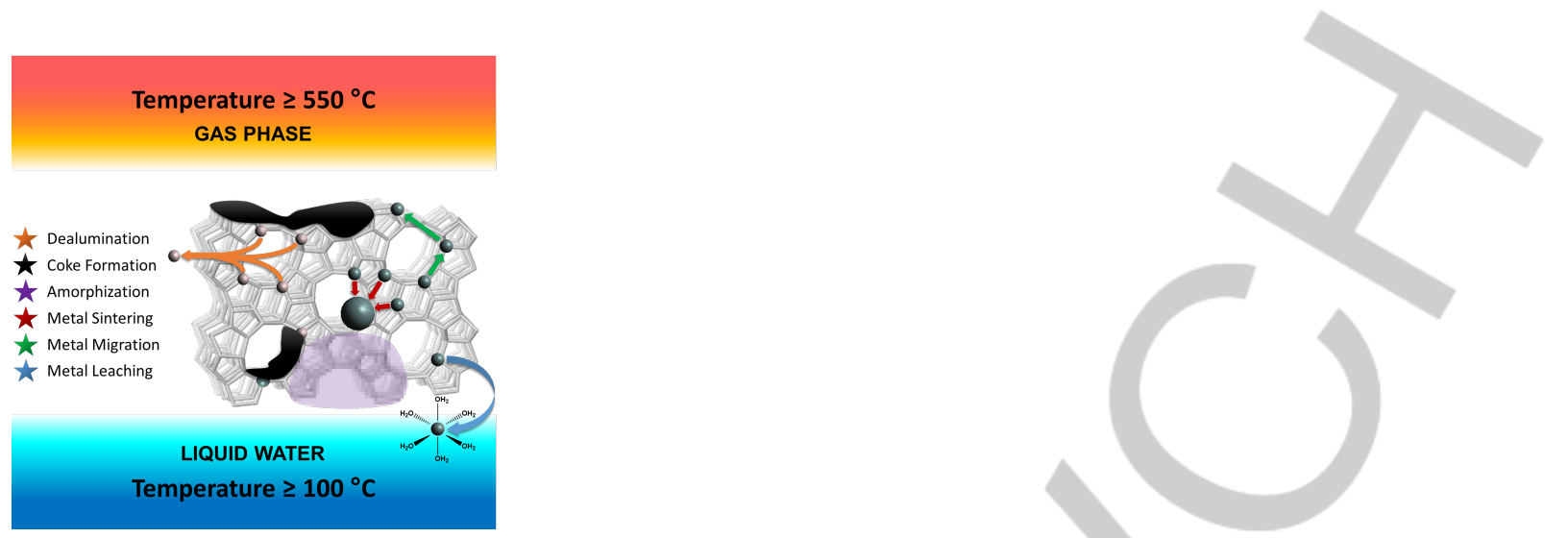

Metal-containing zeolites outside the comfort zone. With a growing demand for the sustainable production of chemicals, new catalysts are vital. Here we highlight recent examples of metal-containing zeolite catalysts operating under harsh conditions in reactions such as high temperature alkane conversion and biomass valorization in liquid water. Specifically, we focus on catalyst stability and recyclability.

Institute and/or researcher Twitter usernames: Catalyse \& Spectro, @labo_Ics; 